\title{
The Wage Response to Shocks: The Role of Inter-Occupational
}

\section{Labour Adjustment*}

\author{
Jeanne Tschopp ${ }^{\aleph}$
}

June 2015

\begin{abstract}
How do cities' average wages adjust to a shock, e.g. trade-induced or technology-induced, shifting the industrial and/or occupational composition of employment? This question is commonly answered using a shift-share analysis, which imputes the effects of composition changes on cities' average wages in a purely mechanical way. This paper argues that a shift-share approach can be misleading if compositional shifts spill over into industrial and occupational wages. Using data on Germany, this paper finds that the spillover effects from a shift in industrial and occupational composition are large and imply a total effect on cities' average wages of 2.8 times the effect that is predicted by a shift-share exercise. In addition, results indicate that in the case of Germany, accounting for adjustments along the occupational mix is crucial to identify these spillovers, even if one is only interested in the effect of an industry-specific shock.
\end{abstract}

JEL classification numbers: J30

Keywords: Wages, Worker Mobility, Spillovers, Industrial and Occupational Composition, Local Labour Markets.

*I would like to thank Gabriel Ahlfeldt, Paul Beaudry, Kenza Benhima, Marius Brülhart, Olivier Cadot, Karolina Ekholm, Ekkehard Ernst, David Green, Jean Imbs, Rafael Lalive, Florian Pelgrin, Benjamin Sand, Pascal St-Amour, Mathias Thoenig, participants at the Doctoral Research Days 2010 in Lausanne, the ProDoc Workshop 2010 in Geneva, the SSES Annual Meeting 2010 in Fribourg, the Macro Workshop 2010 at UBC in Vancouver, the 5th Meeting of the Urban Economics Association 2010 in Denver, the Workshop on Globalization and Labour Market Outcomes 2011 in Geneva and anonymous referees for helpful comments. I am grateful to the Swiss National Science Foundation for their financial support and to the Research Data Centre of the German Federal Employment Agency at the Institute for Employment Research for providing data access.

${ }^{\aleph}$ Department of Economics, Ryerson University, 350 - Victoria St., Toronto, ON, Canada, M5B 2K3; jtschopp@economics.ryerson.ca. 


\section{Introduction}

A large body of literature documents changes in the wage structure in the U.S. and internationally over the last few decades. A well-known fact is that average wages have stagnated since 1970 and understanding why is an important issue. ${ }^{1}$ One populist conjecture is that shifts in the industrial and occupational composition of jobs have contributed to poor labour market outcomes. In particular, many good jobs have been displaced due to technological change and rising globalization pressures, causing average wage growth to slow down as individuals shift employment from good into less desirable jobs. The notion of a good job refers to a job that pays more for the same level of human capital.

The objective of this paper is to evaluate how one can best assess the role of changes in both industrial and occupational structure of employment on cities' average wages in Germany. The common approach to addressing this question is to perform a shift-share analysis, which is a purely mechanical way of imputing the effects of composition changes on cities' average wages. ${ }^{2}$ In the case of a sectoral shift only, such an approach consists in multiplying each industrial wage premium in a base year by the corresponding change in industrial employment shares and then summing up across industries. For instance, consider a city in which the steel industry pays a $20 \%$ wage premium relative to the average and employs $20 \%$ of the workers of the city. Assume that the high-paying steel industry disappears and that its workers switch to other industries which do not pay any premium. In this example, a shift-share exercise predicts that this industrial composition shift gives rise to a $4 \%$ decrease in the average wage of the city, which is modest considering the importance of the decline of the steel industry.

An inherent characteristic of this approach is that it ignores the potential general equilibrium effects that a shift in the industrial and/or occupational composition of employment may cause on within-industry and within-occupation wages. Using the previous example, shift-share assumes that the only channel through which the decline of the high-paying steel industry affects sectoral wages is through standard supply and demand mechanisms (labour reallocation across sectors) but

\footnotetext{
${ }^{1}$ See for instance Acemoglu (2002) and Katz and Autor (1999) for a discussion of changes in the wage structure and earnings inequality.

${ }^{2}$ See for instance Bound and Johnson (1992) and Lemieux (2002) for a discussion of decomposition methods.
} 
that shifting composition towards low-paying industries does not affect wages in other sectors. If the general equilibrium effects are large, a shift-share approach may not provide a good approximation of the effects of employment composition changes on cities' average wages.

Recent work by Beaudry et al. (2012), henceforth BGS, shows that the spillover effects from a shift in industrial composition on within-industry wages can be substantial and that therefore, a shift-share approach can lead to consequential misestimation of the total effect on cities' average wages. Using a search and bargaining model, the authors show that changes in industrial composition affect industrial wages by modifying workers' outside options. In this framework, shifting employment towards high-paying industries improves outside options and translates into higher wages in all sectors of the economy (including the sectors which are not directly affected by the employment shift). The authors propose a way of estimating these sectoral wage spillover effects and show how they can be added to a shift-share analysis to provide a more reliable means of calculating the effects of composition changes on average city wages. Using U.S. Census data over the years 1970 to 2007, they find that a shift in industrial composition generates changes in cities' average wages that are over threefold the magnitude predicted by a shift-share approach.

This paper studies the effects of compositional shifts on cities' average wages using a search and bargaining framework that accounts for potential general equilibrium effects. However, this study differs from BGS in two dimensions. First, the empirical exercise is performed for Germany. Until the 1990s, West German firms were governed by collective sectoral agreements that were negotiated between employer associations and large unions. It is only around the time of its re-unification and economic integration in 1989 that the country shifted towards a more decentralised labour market. Since one can easily conjecture that Germany responds to local forces that differ from those shaping wage setting in the U.S., it is a priori unclear whether Germany also conforms to the predictions of search and bargaining theory and thus, whether shift-share is as inadequate in Germany as it is in the U.S.

Second, this study adds occupations and evaluates the role of both industrial and occupational changes on cities' average wages simultaneously. The approach of BGS is exclusively designed to understand how a shock shifting the sectoral composition of employment (e.g. a trade-induced 
shock) spills over into industrial wages. Such a shock hardly ever produces only one type of adjustment, but is generally accompanied by a change in the occupational structure. An attractive feature of adding occupations is that it allows to separate out within- from across-industry wage spillover effects. Moreover, this extension allows to examine whether disregarding inter-occupational labour adjustment may produce a biased estimate of the sectoral wage spillover effect due to the fact that a change in the occupational structure is unlikely orthogonal to changes in industrial composition.

In addition, a framework that explores the wage effects of sectoral and occupational shifts simultaneously is particularly useful in thinking about shocks that directly affect occupations (e.g. technology, offshoring or outsourcing). A recent literature shows that, likely as a result of technological change, there have been large changes in the occupational structure of the economy, with employment becoming increasingly concentrated at the top and the bottom of the occupational skill distribution. ${ }^{3}$ In light of these recent developments, it appears important to assess whether shifts in the occupational structure of employment also generate general equilibrium wage effects of the type implied by search and bargaining theory.

In order to evaluate the wage effects of both industrial and occupational composition changes simultaneously, the paper decomposes workers' mobility in three dimensions: within industry (across occupations), within occupation (across industries) and across both occupations and industries. The idea underlying this decomposition is that, depending on human capital specificity, an unemployed worker may be more likely to find a job within his prior industry and/or occupation.

Whether human capital is primarily industry- or occupation-specific is important as it possibly affects the set of outside options with which a worker can potentially bargain and, as a result, the extent to which a shift in the industrial versus occupational composition of employment spills over into wages. For instance, in the extreme situation in which human capital cannot be transferred across industries, jobs outside a worker's prior industry do not constitute outside options as the probability of actually switching across industries is zero. In such a case, a shock shifting the occupational structure of employment will generate wage spillovers while one changing indus-

\footnotetext{
${ }^{3}$ For studies on the polarization phenomenon, see for instance Acemoglu and Autor (2011), Autor et al. (2006), Autor et al. (2003), Dustmann et al. (2009), Goos and Manning (2007), Goos et al. (2009) and Spitz-Oener (2006).
} 
trial composition will not create any general equilibrium effects, and this even in the presence of search and bargaining mechanisms. Similarly, if skills are exclusively occupation-specific, shifts in industrial composition only will produce spillover effects.

Several contributions of the human capital literature have discussed the importance of skill specificity and observed mobility for wages and found evidence of both industry-specific (Parent, 2000) and occupation-specific (Kambourov and Manovskii, 2009b; Sullivan, 2010) human capital. While human capital specificity is often associated with the wage losses accompanying job displacement, this paper suggests that skill specificity may affect wages even in the absence of actual labour movements (or shifts in productivity). In particular, search and bargaining mechanisms imply that, by diminishing the threat point in the Nash bargaining game, higher skill specificity translates into lower wages.

Using an instrumental variable strategy, the paper finds that simultaneously accounting for changes in the industrial and occupational composition of employment is crucial to identify their effects on average city wages. In the particular case of Germany, focusing only on industries would lead to the conclusion that the sectoral wage spillover is statistically insignificant and would thus suggest that a shift-share approach is adequate. By contrast, taking into account both changes in the industrial and occupational composition of employment shows that both dimensions generate large wage spillovers effects but that they happen to offset each other because of the co-movements in the two sets of changes. When both dimensions are accounted for, results indicate that the total effect of these composition changes on cities' average wages is 2.8 times - a result very close to that found in the U.S. - as large as would have been suggested by a shift-share approach. Thus, although it may be more centralised than the U.S., Germany also appears to conform to the predictions of search and bargaining theory.

The rest of the paper is organized as follows. Section 2 discusses shift-share analysis. The section emphasizes that the approach may provide a biased estimate of the total effect of a compositional shift on cities' average wages in the presence of general equilibrium effects. Section 3 extends BGS search and bargaining model to illustrate how these general equilibrium effects can araise and in particular, to show how shifts in both industrial and occupational composition of employment can 
spill over into occupation-industry-city-specific wages. In Section 4, the paper describes the instrumental variable strategy used to identify these spillover effects. Section 5 presents the empirical setting. The main results and robustness tests are shown in the next two sections. Section 7 goes back to the initial question and shows how the estimated spillover effects can be combined with a shift-share exercise to quantify the total effect of changes in industrial and occupational structure on city average wages in Germany. Section 8 concludes.

\section{Shift-share analysis}

Shift-share analysis is commonly used to evaluating the impact of changes in the structure of employment on cities' average wages. Consider for instance a shift in the industrial composition of employment in a city. A shift-share approach consists in decomposing changes in the average wage in that city into two components: a "between" component that reflects changes in the employment composition and a "within" component isolating changes in sectoral wages. Specifically,

$$
\begin{aligned}
\Delta w_{c \tau} & =\Delta \sum_{j}^{I} \eta_{j c \tau} w_{j c \tau} \\
& =\sum_{j}^{I} w_{j c(\tau-1)}\left[\eta_{j c \tau}-\eta_{j c(\tau-1)}\right]+\sum_{j}^{I}\left[w_{j c \tau}-w_{j c(\tau-1)}\right] \eta_{j c \tau},
\end{aligned}
$$

where $\Delta w_{c \tau}$ denotes the change in the average wage in city $c$ between time $\tau$ and $(\tau-1), w_{j c \tau}$ is the average wage in industry $j$ and city $c$ at time $\tau, \eta_{j c \tau}$ denotes employment in industry $j$ and city $c$ as a share of city $c$ 's employment at time $\tau$ and $I$ is the total number of industries. The first summation term corresponds to the between component and the second one to the within component.

A shift-share approach attributes the effect of a change in industrial composition to the between component only, assuming that compositional shifts do not affect industry-city wages captured in the within component. Such an approach is theoretically justified in economic models in which employment compositional shifts do not generate wage spillover effects, as it is the case for instance 
in models where wages are determined by supply and demand mechanisms only. However, in the presence of wage spillover effects, a shift-share approach likely misrespresent the total effect of a compositional shift.

To see why this is the case, consider a framework where the industrial composition of employment in city $c$ affects sectoral wages, i.e. $w_{i c \tau}=w_{i c \tau}\left(\eta_{1 c \tau}, \ldots, \eta_{j c \tau}, \ldots, \eta_{I c \tau}\right) \forall i, c$. Suppose that, everything else equal, a city experiences a shift in its industrial composition. Then, looking at infinitesimal changes in employment shares, the total effect on the city's average wage can be written as

$$
\begin{aligned}
d w_{c \tau} & =\sum_{j}^{I} \frac{\partial w_{c \tau}}{\partial \eta_{j c \tau}} d \eta_{j c \tau}+\sum_{i}^{I} \frac{\partial w_{c \tau}}{\partial w_{i c \tau}} \sum_{j}^{I} \frac{\partial w_{i c \tau}}{\partial \eta_{j c \tau}} d \eta_{j c \tau} \\
& =\sum_{j}^{I} w_{j c(\tau-1)} d \eta_{j c \tau}+\sum_{i}^{I} \eta_{i c(\tau-1)} \sum_{j}^{I} \frac{\partial w_{i c \tau}}{\partial \eta_{j c \tau}} d \eta_{j c \tau}
\end{aligned}
$$

where the first component corresponds to the between component and the second component captures the general equilibrium effects that a shift-share approach omits. Using a search and bargaining model with multiple cities and industries, BGS show that these general equilibrium effects are substantial and that therefore, a shift-share approach does not provide a good approximation of the total effect of a shift in industrial composition on a city's average wage.

The main objective of this paper is to propose an approach that allows the evaluation of the effects of shifts in both industrial and occupational composition simultaneously, accounting for these potential wage spillover effects. To do so, the next section discusses how BGS can be extended to occupations with the primary goal of illustrating how, in a search and bargaining framework, both industrial and occupational composition of employment relate to occupation-industry-city wages and therefore, to the second component of equation (2). The paper then estimates the spillover effects of occupational and industrial compositional shifts using an instrumental variable strategy. In the last section, the paper discusses how the estimated spillover effects can be combined with shift-share to quantify the total effects of changes in the industrial and occupational structure of employment. 


\section{Model}

Extending BGS to occupations implies two modifications. The first one introduces some complementarity between occupations in the production function. The second one decomposes workers' mobility in three dimensions: within industry (across occupations), within occupation (across industries) and across both occupations and industries to reflect the idea that an unemployed worker may be more likely to find a job within his or her prior industry and/or occupation. In what follows, the paper focuses on these two modifications and refers to BGS for further details on the model.

\subsection{Setup}

Consider an economy with one final good $Y$, assembled from the economy-wide output of $I$ industries, i.e.

$$
Y=\left(\sum_{i}^{I} a_{i} Z_{i}^{\chi}\right)^{\frac{1}{\chi}}
$$

where $\chi<1, a_{i}$ is a parameter reflecting aggregate demand for the industrial good $i$ and $Z_{i}$ denotes the economy-wide output of industry $i$. The price of the final good is normalised to one and the price of the industrial good $i$ is $p_{i}$. The economy is segmented into $\mathrm{C}$ local labour markets, hereafter cities. The economy-wide output $Z_{i}$ is given by the sum of $Y_{i c}$, the output of industry $i$ produced in city $c$. For clarity, production involves labour only and uses $Q$ occupations indexed by $q$. Production in industry $i$ and city $c$ is given by the following Cobb-Douglas production function

$$
Y_{i c}=A_{i c} \prod_{q}^{Q}\left(N_{q i c}\right)^{\theta_{q i c}}
$$

where $A_{i c}$ is a productivity shifter, $\theta_{q i c}$ is a technology parameter and $N_{q i c}$ denotes employment in occupation $q$, industry $i$ and city $c$.

The labour market considered is characterised by search and matching frictions. For simplicity, this paper assumes that workers can move within but not across cities, focuses on random search 
and ignores resignations as well as on-the-job search. ${ }^{4}$ The model is couched in continuous time. Workers and firms live forever, discount the future at an exogenous rate $\rho$ and are risk neutral. Workers seek to maximize the expected discounted sum of future utility flows, and firms are profit maximisers.

Let $V_{q i c}^{f}$ and $V_{q i c}^{v}$ be the discounted value to firms of a filled position and a vacancy for occupation $q$, industry $i$ and city $c$. Define $\lambda_{q i c}=p_{i} \theta_{q i c} \frac{Y_{i c}}{N_{q i c}}$, the value of the marginal product of type-q labour in industry $i$ and city $c$. If a position is filled, it generates a flow of profits of $\left(\lambda_{\text {qic }}-w_{\text {qic }}\right)$. With layoffs occuring at the exogenous rate $\delta$, the discounted value of profits from a filled position is given by

$$
\rho V_{q i c}^{f}=\left(\lambda_{q i c}-w_{q i c}\right)+\delta\left(V_{q i c}^{v}-V_{q i c}^{f}\right)
$$

Assuming that there are no costs to maintaining a vacant position, the discounted value of profits from a vacant position satisfies

$$
\rho V_{q i c}^{v}=\phi_{c}\left(V_{q i c}^{f}-V_{q i c}^{v}\right)
$$

where $\phi_{c}$ is the probability that a firm fills a posted vacancy.

In this economy, workers are either employed or unemployed in a given period. Let $U_{q i c}^{e}$ and $U_{q i c}^{u}$ be the discounted value to workers of being employed and unemployed in occupation $q$, industry $i$ and city $c$, respectively. An employed worker earns the wage $w_{\text {qic }}$ and becomes unemployed with probability $\delta .{ }^{5}$ Thus, the discounted value of being employed satisfies

$$
\rho U_{q i c}^{e}=w_{q i c}+\delta\left(U_{q i c}^{u}-U_{q i c}^{e}\right)
$$

The probability of an unemployed individual finding a job in the subsequent period is $\psi_{c}$. The probability that the vacancy is from a particular occupation-industry cell depends on the extent to

\footnotetext{
${ }^{4}$ See Beaudry et al. (2012) for a discussion on the implications of relaxing these assumptions.

${ }^{5}$ For clarity, any relevant city-specific features such as amenities and unemployment benefits are normalized to zero. Qualitative results are not altered by this simplification.
} 
which individuals can actually switch industry and/or occupation. The paper proposes to distinguish between three dimensions of mobility: within-industry, within-occupation and unrestricted mobility (i.e. mobility across the entire occupation and industry matrix). To capture these dimensions, it is assumed that the probability of a worker getting a random draw from his prior industry is $\varphi^{I N D}$, while $\varphi^{O C C}$ is the probability of a worker getting a random draw from his prior occupation. This assumption implies that the importance of within-industry (across occupations) and withinoccupation (across industries) mobility can be capured by $\varphi^{I N D}\left(1-\varphi^{O C C}\right)$ and $\left(1-\varphi^{I N D}\right) \varphi^{O C C}$, respectively, while the probability $\left(1-\varphi^{I N D}\right)\left(1-\varphi^{O C C}\right)$ reflects unrestricted mobility. ${ }^{6}$ Thus, if a worker in city $c$ gets a draw from his or her prior industry (in this case industry $i$ ), the probability of him or her finding a job in occupation $r$ is given by $\psi_{c} \varphi^{I N D}\left(1-\varphi^{O C C}\right) \eta_{r c, i}$, where $\eta_{r c, i}$ denotes occupation- $r$ employment as a share of industry $i$ employment in city $c$. Similarly, if a worker in city $c$ gets a draw from his or her prior occupation (here occupation $q$ ), the probability of him or her finding a job in industry $j$ is given by $\psi_{c} \varphi^{O C C}\left(1-\varphi^{I N D}\right) \eta_{j c, q}$, where $\eta_{j c, q}$ denotes industry- $j$ employment as a share of occupation $q$ employment in city $c$. Finally, in the case of unrestricted mobility, the probability of a worker finding a job in industry $j$ and occupation $r$ is given by $\psi_{c}\left(1-\varphi^{I N D}\right)\left(1-\varphi^{O C C}\right) \eta_{r j c}$, where $\eta_{r j c}$ is the fraction of city c's employment in industry $j$ and occupation $r .{ }^{7}$ Therefore, the discounted value of being unemployed in occupation $q$, industry $i$ and city $c$ satisfies the following relationship

$$
\begin{aligned}
\rho U_{q i c}^{u} & =\psi_{c}\left[\varphi^{I N D} \varphi^{O C C} U_{q i c}^{e}+\left(1-\varphi^{I N D}\right) \varphi^{O C C} \sum_{j}^{I} \eta_{j c, q} U_{q j c}^{e}\right. \\
& \left.+\varphi^{I N D}\left(1-\varphi^{O C C}\right) \sum_{r}^{Q} \eta_{r c, i} U_{r i c}^{e}+\left(1-\varphi^{I N D}\right)\left(1-\varphi^{O C C}\right) \sum_{j, r}^{I \cdot Q} \eta_{r j c} U_{r j c}^{e}-U_{q i c}^{u}\right] .
\end{aligned}
$$

Importantly, if $\varphi^{I N D}=\varphi^{O C C}=1$, the utility of being unemployed in occupation $q$, industry $i$ and city $c$ only depends on the utility of being employed in that same occupation-industry-city cell as the probability of getting a draw from any other occupation and industry is zero. However, if

\footnotetext{
${ }^{6} \mathrm{~A}$ worker is immobile if $\varphi^{I N D}=\varphi^{O C C}=1$, imperfectly mobile if $\varphi^{I N D}$ and $\varphi^{O C C} \in(0,1)$ and perfectly mobile if $\varphi^{I N D}=\varphi^{O C C}=0$.

${ }^{7}$ Section A of the Web Appendix provides an illustration of mobility in a two-by-two occupation-industry model. Section B of the Web Appendix shows some stylized facts on industrial and occupational mobility in Germany.
} 
$\varphi^{I N D}$ and $\varphi^{O C C} \in(0,1)$, the utility of being unemployed is a function of the utility of employment associated with jobs in other occupations and industries. Whether or not an unemployed individual gets a random draw from his or her prior industry/occupation plays an important role in the wage determination process because it determines the set of outside options with which a worker can potentially bargain.

The number of matches produced per unit of time, denoted by $M$, is given by the following matching technology

$$
M=m\left(\left(L_{c}-E_{c}\right),\left(N_{c}-E_{c}\right)\right)
$$

where $L_{c}-E_{c}$ is the level of unemployment in city $c$ and $N_{c}-E_{c}$ is the number of vacancies. ${ }^{8}$ The matching technology is of the Cobb-Douglas type, exhibits constant returns to scale and is increasing in both its arguments. Given the matching technology, the probability that an unemployed worker meets any vacancy and that a firm fills a vacancy are given by

$$
\psi_{c}=\frac{\delta E R_{c}}{1-E R_{c}} \quad \text { and } \quad \phi_{c}=\left(\frac{1-E R_{c}}{\delta E R_{c}}\right)^{\frac{\sigma}{1-\sigma}}
$$

respectively, where $E R_{c}$ denotes the employment rate in city $c$.

Once matches are made, workers and firms bargain over the wage rate in a complete information context. Wages are set by the following bargaining rule, with disagreement points (outside options) $V_{q i c}^{v}$ and $U_{q i c}^{u}$ for firms and workers, respectively

$$
\left(V_{q i c}^{f}-V_{q i c}^{v}\right)=\left(U_{q i c}^{e}-U_{q i c}^{u}\right) \kappa,
$$

where $\kappa \in[0,1]$ is the relative bargaining power of firms and workers.

The steady state is characterized by values of $E R_{c}, w_{q i c}$ and $N_{q i c}$. At the aggregate level, prices adjust such that markets for industrial goods clear. Prices react to shifts in demand for industrial goods, as captured by $a_{i}$. Local outcomes respond to changes in industry prices $p_{i}$, technology parameters $\theta_{\text {qic }}$ and productivity shifters $A_{i c}$.

\footnotetext{
${ }^{8}$ Implications of two-sided heterogeneity and possible assortative matching are left for future research.
} 


\subsection{Wage equation}

The wage equation is obtained by substituting (3)-(6) into (9). The wage in occupation $q$, industry $i$ and city $c$ is given by

$$
\begin{aligned}
w_{q i c} & =\gamma_{1 c} \lambda_{q i c}+\gamma_{2 c}\left[\left(1-\varphi^{I N D}\right) \varphi^{O C C} \sum_{j}^{I} \eta_{j c, q} w_{q j c}\right. \\
& \left.+\varphi^{I N D}\left(1-\varphi^{O C C}\right) \sum_{r}^{Q} \eta_{r c, i} w_{r i c}+\left(1-\varphi^{I N D}\right)\left(1-\varphi^{O C C}\right) \sum_{j, r}^{I \cdot Q} \eta_{r j c} w_{r j c}\right],
\end{aligned}
$$

where the coefficients are functions of the parameters of the model and of the city's employment rate. $^{9}$

The summation terms in the brackets reflect workers' outside options and come from the discounted utility of being unempoyed. If the probability of an unemployed worker getting a draw from his or her prior occupation and industry is one (i.e. $\varphi^{I N D}=\varphi^{O C C}=1$ ), wages are determined by some fraction of the marginal product of labour $\left(\lambda_{\text {qic }}\right)$ only as wages in other occupations and industries do not constitute options with which to bargain. However, if $\varphi^{I N D}$ and $\varphi^{O C C} \in$ $(0,1)$, the discounted utility of being unemployed in occupation $q$, industry $i$ and city $c$ is a function of the utility of being employed in other occupations and industries, implying that wages are also determined by within-occupation $\left(\sum_{j} \eta_{j c, q} w_{q j c}\right)$, within-industry $\left(\sum_{r} \eta_{r c, i} w_{r i c}\right)$ and within-city $\left(\sum_{j, r} \eta_{r j c} w_{r j c}\right)$ average wages. For example, in such a case, equation (10) suggests that the wage of a routine worker in the manufacturing industry in Münich depends on the average wage paid to routine workers in Münich, the average wage paid in the manufacturing industry in Münich and on the overall average city wage. In what follows, the paper considers the case where $\varphi^{I N D}$ and $\varphi^{O C C}$ $\in(0,1)$.

In this framework, the sectoral and occupational composition of employment in a city affect

\footnotetext{
${ }^{9}$ In particular,

$$
\begin{aligned}
\gamma_{1 c} & =\frac{\left(\rho+\delta+\psi_{c} \varphi^{I N D} \varphi^{O C C}\right)}{\left[\left(\rho+\delta+\psi_{c} \varphi^{I N D} \varphi^{O C C}\right)+\kappa\left(\rho+\delta+\phi_{c}\right)\right]} \\
\gamma_{2 c} & =\frac{\left(\rho+\delta+\phi_{c}\right) \kappa}{\left[\left(\rho+\delta+\psi_{c} \varphi^{I N D} \varphi^{O C C}\right)+\kappa\left(\rho+\delta+\phi_{c}\right)\right]} \frac{\psi_{c}}{\left(\rho+\delta+\psi_{c}\right)}
\end{aligned}
$$
}

where $\phi_{c}$ and $\psi_{c}$ are functions of the employment rate. 
occupation-industry-city wages because they determine within-occupation, within-industry and within-city average wages and, as a consequence, workers' outside options. In this sense, one can think of within-occupation and within-industry average wages as reflecting the (within-occupation) industrial and (within-industry) occupational composition of employment in a city, respectively. In general, equation (10) suggests that cities with a composition of employment that is skewed towards high-paying occupations and industries will pay higher wages, as a more favourable employment composition translates into a higher threat point in the bargaining game.

A particularity of equation (10) is that, since an increase in wages in an industry and/or occupation of the economy constitutes an improvement in workers' outside options, wages act as strategic complements, which means for instance that an increase in wages for abstract workers in the tertiary sector in Münich generates a positive spillover effect on routine workers in the manufacturing industry in the same city. This strategic complementarity implies that any change in the sectoral or occupational composition of employment generates several rounds of wage adjustment. Thus, the parameters $\gamma_{2 c}\left(1-\varphi^{I N D}\right) \varphi^{O C C}, \gamma_{2 c} \varphi^{I N D}\left(1-\varphi^{O C C}\right)$ and $\gamma_{2 c}\left(1-\varphi^{I N D}\right)\left(1-\varphi^{O C C}\right)$ only capture partial spillover effects of a change in within-occupation, within-industry or within-city employment, respectively. These partial effects depend on city-specific employment rates (through $\gamma_{2 c}$ ), which are themselves determined endogenously.

In order to obtain the total spillover effects, it is useful to solve equation (10) for wages and explicate the relationship between occupation-industry-city wages and the employment rate. To do so, the paper takes a log-linear approximation around the point where cities have an identical structure of employment. ${ }^{10}$ One obtains,

$$
\Delta \ln w_{q i c \tau}=\Delta d_{q i \tau}+\beta_{1} \Delta R_{q c \tau}^{I N D}+\beta_{2} \Delta R_{i c \tau}^{O C C}+\beta_{3} \Delta R_{c \tau}^{C I T Y}+f_{q i} \Delta E R_{c \tau}+\Delta \xi_{q i c \tau},
$$

where $\Delta$ denotes a first difference with respect to time $\tau$ and $f_{q i}$ is an occupation-industry-specific positive term obtained from the linear approximation. In the empirical section, $\Delta d_{q i \tau}$ denotes an

\footnotetext{
${ }^{10}$ Derivation details are provided in Section C of the Web Appendix. Note that linearizing equation (10) with a first-order approximation may be an empirical issue if higher-order terms are correlated with the regressors of interest. In their Web Appendix, BGS present results of a Monte Carlo simulation evaluating their first-order linear approximation. They conclude that the wage generation process is not essentially non-linear.
} 
entire set of occupation-industry time-varying dummies and captures components of changes in the value of the marginal product of labour that do not vary across cities. $\Delta \xi_{q i c \tau}$ corresponds to the error term and is a function of the unobserved city-specific components of changes in productivity associated with occupation $q$, industry $i$ and city $c$.

$R_{q c \tau}^{I N D}, R_{i c \tau}^{O C C}$ and $R_{c \tau}^{C I T Y}$ are indices reflecting workers' outside options and capturing the (within-occupation) industrial, (within-industry) occupational and city composition of employment on occupation-industry-city wages. These indices are defined as

$$
R_{q c \tau}^{I N D}=\sum_{j}^{I} \eta_{j c \tau, q} \nu_{q j \tau}, \quad R_{i c \tau}^{O C C}=\sum_{r}^{Q} \eta_{r c \tau, i} \nu_{r i \tau} \quad \text { and } \quad R_{c \tau}^{C I T Y}=\sum_{j, r}^{I \cdot Q} \eta_{r j c \tau} \nu_{r j \tau}
$$

where $\nu_{q i \tau}$ denotes the national wage premium in occupation $q$ and industry $i$ relative to some numeraire occupation and industry. ${ }^{11}$ The total spillover effects of a shift in industrial, occupational and city composition of employment are given by

$$
\begin{aligned}
& \beta_{1}=\frac{\gamma_{2}}{1-\gamma_{2}\left(1-\varphi^{I N D} \varphi^{O C C}\right)}\left(1-\varphi^{I N D}\right) \varphi^{O C C} \geq 0 \\
& \beta_{2}=\frac{\gamma_{2}}{1-\gamma_{2}\left(1-\varphi^{I N D} \varphi^{O C C}\right)} \varphi^{I N D}\left(1-\varphi^{O C C}\right) \geq 0 \\
& \beta_{3}=\frac{\gamma_{2}}{1-\gamma_{2}\left(1-\varphi^{I N D} \varphi^{O C C}\right)}\left(1-\varphi^{I N D}\right)\left(1-\varphi^{O C C}\right) \geq 0,
\end{aligned}
$$

respectively. With $\varphi_{I N D}$ and $\varphi_{O C C} \in[0,1]$, the $\beta$ s are nonnegative. Finally, note that the mobility terms can be identified as follows

$$
\varphi_{I N D}=\frac{\beta_{2}}{\beta_{2}+\beta_{3}} \quad \text { and } \quad \varphi_{O C C}=\frac{\beta_{1}}{\beta_{1}+\beta_{3}} .
$$

\section{Identification strategy}

This section discusses how the total spillover effects $\beta_{1}, \beta_{2}$ and $\beta_{3}$ can be identified. Once estimates of these spillovers are obtained, one can compute the total effect of a shift in the composition of employment on a city's average wage. Let $t$ denote an individual year and $\tau$ denote a five-year

\footnotetext{
${ }^{11}$ Implications of allowing workers to move across cities are discussed in Section D of the Web Appendix.
} 
period. The equation of interest is estimated using five-year averages of annual data taking mutually exclusive and jointly exhaustive intervals over the period 1977-2001. ${ }^{12}$

The main issue in estimating these spillovers is that shifts in the composition indices as well as in the employment rate are likely correlated with the error term. This endogeneity issue is due to the potential correlation between employment shares and the city-specific components of changes in productivity left in the error term. ${ }^{13}$

The paper uses Bartik-style instruments, constructed using predicted employment shares. Future employment in occupation $q$, industry $i$ and city $c$ is predicted as if start-of-period employment had grown according to the national trend, i.e.

$$
\hat{N}_{q i c t}=N_{q i c(t-6)} \frac{N_{q i t}}{N_{q i(t-6)}},
$$

where ${ }^{\wedge}$ denotes a prediction and $N_{\text {qit }}$ is national occupation-industry employment. $\hat{N}_{q i c \tau}$ is computed as the mean of $\hat{N}_{\text {qict }}$ over the corresponding five-year interval and the corresponding predicted employment shares are constructed as follows

$$
\hat{\eta}_{r c \tau, i}=\frac{\hat{N}_{r i c \tau}}{\hat{N}_{i c \tau}},
$$

where $\hat{N}_{i c \tau}=\sum_{q}^{Q} \hat{N}_{q i c \tau}$. The assumption ensuring the exogeneity of predicted employment shares is that past and changes in past occupation-industry-city employment is uncorrelated with future shocks to the city-specific components of productivity.

The paper then uses predicted employment shares to construct instruments for the composition indices and for the employment rate. In principle, one could use the predicted counterpart of each endogenous variable as an instrument for the endogenous variable. The drawback of such an approach is that it would not allow to test for the validity of the exogeneity condition. In order to perform a test of the over-identifying restrictions, the predicted counterpart of each endogeneous

\footnotetext{
${ }^{12}$ This reduces measurement error and purges variations due to business cycles.

${ }^{13}$ The endogeneity issue and its treatment is completely symmetric to that of BGS. Section E of the Web Appendix shows why the composition indices are correlated with the error term. For a more detailed discussion on the issue, see BGS.
} 
variable is decomposed into two components.

Instruments for the composition indices To understand the nature of the instruments, it is useful to decompose each composition index into a between and a within component, each reflecting a different source of data variation. The first component summarizes changes in the index that are associated with changes in employment shares. The second component captures variation attributable to changes in the wage premia. For instance, the occupational composition index can be decomposed as follows

$$
\Delta R_{i c \tau}^{O C C}=\sum_{r}^{Q} \nu_{r i(\tau-1)} \Delta \eta_{r c \tau, i}+\sum_{r}^{Q} \eta_{r c \tau, i} \Delta \nu_{r i \tau}
$$

where the first term is the between component and the second one is the within component. Importantly, each of these two components affects the composition index equally, which implies that there exists two very different sources of variation that can be used to construct instruments.

The first instrument focuses on variation in predicted employment shares, i.e. it is constructed as follows,

$$
I V^{O C C, B E T W E E N}=\sum_{r}^{Q} \nu_{r i(\tau-1)} \Delta \hat{\eta}_{r c \tau, i},
$$

where $\hat{\eta}_{r c \tau, i}=\frac{\hat{N}_{r i c \tau}}{\sum_{r} \hat{N}_{r i c \tau}}$. Since it uses predicted employment shares, this instrument isolates variation stemming from a national-level demand shift (e.g. a trade shock) distributed across cities according to start-of-period employment shares. The second instrument targets the within component and focuses on shifts in wage premia (e.g. induced by a technology shock), i.e.

$$
I V^{O C C, W I T H I N}=\sum_{r}^{Q} \hat{\eta}_{r c \tau, i} \Delta \nu_{r i \tau} .
$$

It is important to note that while these two instruments reflect changes that may result from two different shocks, both are equally important for identification as they provide different sources of variation that affect the composition index in the same way. Therefore, identification of the 
spillover effects does not require being certain about the source of the shock underlying the shift in the composition index, but instead requires that there be sufficient data variation along the between and within dimensions.

The instruments for the industrial and city composition indices are constructed in a similar way. In particular,

$$
I V^{I N D, B E T W E E N}=\sum_{j}^{I} \nu_{q j(\tau-1)} \Delta \hat{\eta}_{j c \tau, q} \quad \text { and } \quad I V^{I N D, W I T H I N}=\sum_{j}^{I} \hat{\eta}_{j c \tau, q} \Delta \nu_{q j \tau}
$$

are used for the industrial composition index and

$$
I V^{C I T Y, B E T W E E N}=\sum_{j, r}^{I \cdot Q} \nu_{r j(\tau-1)} \Delta \hat{\eta}_{r j \tau} \quad \text { and } \quad I V^{C I T Y, W I T H I N}=\sum_{j, r}^{I \cdot Q} \hat{\eta}_{r j c \tau} \Delta \nu_{r j \tau}
$$

are used as instruments for the city composition index.

Instruments for the employment rate To deal with the endogeneity of the employment rate, the paper constructs a Bartik instrument, i.e.

$$
I V^{E M P L G R O W T H}=\sum_{i, r}^{I \cdot Q} \hat{\eta}_{r i c(\tau-1)} \frac{N_{\text {ri }}}{N_{r i(\tau-1)}}
$$

By predicting local employment growth only, the Bartik instrument targets the numerator of the employment rate. To account for changes driven by shifts in the labour force, the paper proposes to construct the workforce counterpart of the Bartik instrument. That is,

$$
I V^{\text {WORKFORCE }}=\sum_{i, r}^{I \cdot Q} \hat{\eta}_{r i c(\tau-1)}^{w f} \frac{N_{r i \tau}^{w f}}{N_{r i(\tau-1)}^{w f}}
$$

where $N_{\text {qic }}^{w f}$ denotes the workforce, $\eta_{q i c}^{w f}$ is the corresponding workforce share in occupation $q$, industry $i$ and city $c$ and $N_{q i}^{w f}$ detotes the national workforce. 


\section{$5 \quad$ Empirical setting}

\subsection{Data source}

This paper uses the anonymous IAB Employment Sample (IABS) for the years 1975-2001. ${ }^{14}$ Access to the data is provided via a Scientific Use File supplied by the Research Data Centre (FDZ) of the German Federal Employment Agency (BA) at the Institute for Employment Research (IAB). All employees registered by the German social insurance system and subject to social insurance contributions are covered by the IAB employment statistics (the self-employed are not covered). In 1995 for instance, $79.4 \%$ of all employed persons in West Germany was covered by the data. As information on hours worked is not available, this paper concentrates on full-time workers. Wages, measured as daily wages, include all earnings subject to statutory social security contributions and reported at least once annually. Reported income is truncated from above and from below. The upper limit corresponds to the contribution assessment ceiling for social insurance and is adapted annually to the growth of nominal wages. The minimum wage determines the lower limit. The Scientific Use File offers a $2 \%$ anonymous sample of the original IAB employment database. The sample is drawn from four clusters; German nationals, foreign nationals, West German residents and East German residents. This study focuses on West German residents, aged 16 to 62, over the period 1977-2001. East Germany is not included as data is available only from 1991 onwards.

In the original IAB file, industries are classified according to the 1973 3-digit German classification of economic activities, which has no evident correspondence with NACE or ISIC. Occupations are classified according to the 1975 German classification of occupations. The anonymous sample provides only 16 industries and 130 occupations. This paper groups occupations into 33 broader categories, according to the 1975 German classification of occupations. Cities are defined as commuting areas, according to the Federal Office for Building and Regional Planing. This yields 38 local labour markets. ${ }^{15}$

\footnotetext{
${ }^{14}$ Subsection 5.1 draws heavily on Tschopp (2015).

${ }^{15}$ The industrial, occupational and cities classifications are shown in Section F of the Web Appendix.
} 


\subsection{Wage premia}

The dependent variable is estimated from Mincer equations: for each industry and year, log individual wages are regressed on a vector of individual characteristics and a complete set of occupation-city interactions. In performing $i \times t$ regressions, returns to skill are allowed to vary over time and across industries. Let $d_{q}$ be occupation dummies, $d_{c}$ city dummies, $d_{q c}$ be occupation-city interactions and $W_{k}$ be the wage of individual $k . W_{k}$ is expressed in euros and converted into real wages using the consumer price index, base 2005, provided by the German federal statistical office. $Z$ is a vector of individual characteristics consisting of age, the square of age, a gender dummy, a nationality dummy, a categorical variable for education and a full set of education-gender, education-nationality and education-age interactions. For each $i$ and $t$, the paper estimates

$$
\ln W_{k q c}=\varrho_{0}+Z \varrho+d_{q c}+\zeta_{k q c},
$$

where $\zeta_{k q c}$ is an error term. Equation (14) is estimated with OLS. For each industry and year, the dependent variable $w_{\text {qic }}$ is computed using five-year averages of the coefficients on the occupationcity dummies. The national wage premia are obtained in a similar way, by averaging the coefficients on the occupation-city dummies at the national level, and then by averaging over five years. ${ }^{16}$

\section{Main results}

Baseline specification versus omitting occupations Column (1) of Table 1 shows IV estimates for the baseline specification. ${ }^{17}$ In all that follows, standard errors are clustered at the city level. The conventional IV diagnostic tests are satisfactory. ${ }^{18}$ As predicted by the theory, the estimated spillover effects are positive. The size of the coefficients on the industrial, occupational

\footnotetext{
${ }^{16}$ The German wage bargaining system combines elements of both industry-wide collective agreements and decentralised individual agreements between employer and employee. The mechanism described in this paper is the result of decentralised wage bargaining. The effect of industry-wide unions, which establish minimum wages, is captured by the constant term in (14).

${ }^{17}$ The model suggests that the coefficient on the employment rate should vary across occupations and industries. For computational reasons, it is imposed to be constant in a city. In the estimation based on a coarser occupation classification of occupations and industries, the paper finds that letting the employment rate vary in the occupationindustry dimension or imposing it to be constant leads to quantitatively similar results.

${ }^{18}$ First-stage regressions are available upon request.
} 
and city composition indices is $1.07,2.75$ and 0.65 , respectively, although the last coefficient is statistically insignificant. These estimates suggest that shifts in the occupation mix generate wage spillover effects that are at least as important as those generated by a change in the industry mix. This is an important finding as sluggish city wage growth is often associated to industrial composition only. Instead, this result suggest that shift in the occupational composition is responsible as well. The implied $\varphi^{I N D}$ and $\varphi^{O C C}$ are 0.83 and 0.58 , respectively, indicating that moving costs to workers are rather high. Even though these estimates suggest a higher mobility across occupations, a direct comparison of the mobility parameters is difficult, as the aggregation of industries is twice that of occupations.

These first results support BGS findings according to which wages conform to the predictions of search and bargaining theory. The spillover effects generated by a shift in the composition of employment are large, suggesting that the second term of equation (2) is non-zero and that therefore, a shift-share approach leads to misrepresent the total effect of compositional changes on city average wages. Section 7 discusses how these estimates can be used to compute the total effect.

The second part of Table 1 presents results obtained with BGS specification that omits occupations. The goal of this exercise is to compare the approach taken in this paper with one that focuses on industries only and to evaluate whether accounting for inter-occupational labour adjustment may be important even if one only cares about the effects of an industry-specific shock. An approach that focuses on industries only estimates the following equation

$$
\Delta w_{i c \tau}=\Delta d_{q i \tau}+\alpha \Delta \tilde{R}_{c \tau}^{I N D}+f \Delta E R_{c \tau}+\Delta \xi_{i c \tau}
$$

where $w_{i c \tau}$ is the industry-city-specific wage adjusted for observable workers' characteristics. As for the baseline, equation (15) includes an entire set of occupation-industry time-varying dummies and controls for changes in the city-specific employment rate. The error term is $\Delta \xi_{i c \tau}$. The term $\tilde{R}_{c \tau}^{I N D}$ corresponds to the industrial composition index and is constructed as follows

$$
\tilde{R}_{c \tau}^{I N D}=\sum_{j}^{I} \eta_{j c \tau} \nu_{j \tau}
$$


where $\eta_{j c \tau}$ represents employment in industry $j$ and city $c$, as a share of city $c$ 's employment at time $\tau$, and where $\nu_{j \tau}$ denotes industry $j$ 's national wage premium. Both $w_{j c \tau}$ and $\nu_{j \tau}$ are computed using Mincer wage regressions, in a way similar to $w_{q i c \tau}$ and $\nu_{q j \tau}$. The instruments (and predicted employment) for the industrial composition index follow the logic described in Section 4 and are given by

$$
I \tilde{V}^{I N D, B E T W E E N}=\sum_{j}^{I} \nu_{j(\tau-1)} \Delta \hat{\eta}_{j c \tau} \quad \text { and } \quad I \tilde{V}^{I N D, W I T H I N}=\sum_{j}^{I} \hat{\eta}_{j c \tau} \Delta \nu_{j \tau}
$$

where $\hat{\eta}_{j c \tau}=\left(\hat{N}_{j c \tau} / \hat{N}_{c \tau}\right), \hat{N}_{j c \tau}$ denotes predicted employment in industry $j$ and city $c$ at time $\tau$ and $\hat{N}_{c \tau}=\sum_{i}^{I} \hat{N}_{i c \tau}$.

Results for this specification are shown in column 2 of Table 1. First-stage F-statistics and the Hansen test are well behaved. However, the coefficient capturing the spillover effect is negative, -0.19 , and statistically insignificant. Thus, in the particular case of Germany, an approach which omits occupations leads to reject the predictions of search and bargaining theory and to conclude that a shift-share exercise is appropriate.

However, column (1) of the same table suggests that this statistically insignificant and negative estimate may be the result of omitting inter-occupational labour adjustments, which are rarely uncorrelated with sectoral shifts in employment. In the particular case where sectoral and occupational labour adjustments work at cross-purposes, e.g. employment shifts towards high-paying industries but low-paying occupations (or the reverse), omitting one dimension of the adjustment may create a downward biased estimate of the spillover effect. ${ }^{19}$ This idea is supported by Figure 1 which shows the evolution of $\tilde{R}_{c \tau}^{I N D}$ and its occupational counterpart, averaged across cities of Germany, over the period 1980-2001. The figure indicates a tendency for labour to shift towards

\footnotetext{
${ }^{19}$ Conceptually speaking, are there reasons to believe that sectoral and occupational labour adjustments to shocks could offset each other? To fix ideas, think of a trade shock - a reduction in trade costs in a two-by-two economy (skilled vs. unskilled labour, skill-intensive vs. unskilled-intensive industries). The Stolper-Samuelson theorem predicts that if Home is skill-abundant, the skill-intensive sector will expand (a sectoral labour adjustment), but every industry will become less skill-intensive (an occupational labour adjustment). Thus, in the case of a trade shock, the negative relationship between sectoral and occupational shifts in employment is precisely what is to be expected, because the second is endogenous to the first. In that case, the effect of the inter-sectoral shift on the local economy's average wages is certainly be understimated by shift-share analysis, but it will also be underestimated by BGS's procedure, because it will be confounded with the opposite effect of the occupational shift.
} 
high wage premia industries but low wage premia occupations.

Table 1 therefore suggests that accounting for occupations is important, first, for testing the existence of wage spillover effects, second, for appropriately estimating the spillover effects of a shift in industrial composition and, third, because it allows to separate the spillover effects generated by within-industry across-occupation and within-occupation across-industry labour adjustments.

City-specific controls To control for competing explanations for differences in wages (or growth performance) across cities, a vector of city-specific controls is added to the baseline model. Results are shown in Table 2. Column (1) corresponds to the baseline specification. Column (2) controls for potential education externalities. These are captured by the percentage of workers with universitylevel qualifications, denoted $B A_{c \tau} \cdot{ }^{20}$ The diversity of employment across industries and occupations is controlled for in column (3). It is measured using the lag of one minus the industrial Herfindahl index, $(1-H E R F)_{c \tau}^{I N D}=\left(1-\sum_{i}^{I} \eta_{i c(\tau-1)}^{2}\right)$, and with the lag of one minus the occupational Herfindahl index, $(1-H E R F)_{c \tau}^{O C C}=\left(1-\sum_{q}^{Q} \eta_{q c(\tau-1)}^{2}\right) .{ }^{21}$ Finally, the paper controls for city size in column (5) using the log of the city labour force, denoted $\ln S I Z E_{c \tau} \cdot{ }^{22}$ Following the existing literature, one would expect the effect on each of these measures to be positive. Column (5) includes all of these additional city-specific controls jointly.

The inclusion of additional regressors does not alter the results, suggesting that composition indices are not capturing alternative driving forces for city-level wage changes. Whichever specification considered, the coefficients on the variables of interest are stable and similar to the baseline estimates. The coefficients on industrial and occupational composition indices remain significant at the one percent level. Education tends to have a positive and statistically significant effect on average wages, which supports the findings of e.g. Moretti (2004) and Acemoglu and Angrist (2000). The diversity of employment has a positive impact on average wages. But only industrial diversity triggers a statistically significant effect on average wages. Changes in city size, as captured by

\footnotetext{
${ }^{20}$ Alternatively, one could proxy city-level education with city average education level. Whether one or the other measure is used, the effect of education remains similar and does not alter the estimated coefficients on the indices.

${ }^{21}$ To avoid any endogeneity issue related to employment, Herfindahl indices are introduced in the estimation with one lag.

${ }^{22}$ Results are unaltered if one instruments $\ln S I Z E_{c \tau}$ using its predicted counterpart (i.e. using $\hat{N}_{c \tau}^{w f}=\sum_{i, q}^{I \cdot Q} \hat{N}_{q i c \tau}^{w f}$, where $\hat{N}_{q i c \tau}^{w f}$ is constructed as predicted in Section 4).
} 
$\ln S I Z E_{c \tau}$, are positive but rather small and statistically insignificant, supporting Blanchard and Katz (1992).

Section $\mathrm{H}$ of the Web Appendix presents an additional set of regressions that test the robustness of the results found in Tables 1 and 2. These regressions include testing the sensitivity of the results to various levels of industrial and occupational aggregation, dealing with the selection of workers into cities and occupations, and using French data as an alternative to the German data to construct instruments for the composition indices. The estimates on industrial and occupational composition are fairly robust across specifications.

\section{Evaluating the total effects on cities' average wages}

The goal of the paper is to evaluate how one can best assess the role of changes in both the industrial and occupational structure of employment on cities' average wages in Germany, while accounting for the potential wage spillover effects that a shift in the composition of employment may have on within-industry and within-occupation wages. So far, the paper has focused on testing the existence of these general equilibrium effects and estimating their magnitude. As it turns out, estimates of the spillover effects of a shift in industrial and occupational composition are large. In this section, the paper shows how these estimates can be combined with a shift-share approach to compute the total effect of a shift in industrial and occupational composition on cities' average wages.

Suppose that a city $c$ experiences a shift in its composition of employment but that everything else remains constant (in particular, assume that the national wage premia remain constant, i.e. $\left.\Delta \nu_{r j \tau}=0 \forall r, j\right)$. Disaggregating the analysis at the occupation-industry-city level, the total effect on the city's average wage can be written as

$$
d w_{c \tau}=\sum_{j, r}^{I \cdot Q} \frac{\partial w_{c \tau}}{\partial \eta_{r j c \tau}} d \eta_{r j c \tau}+\sum_{i, q}^{I \cdot Q} \frac{\partial w_{c \tau}}{\partial w_{q i c \tau}} \sum_{j, r}^{I \cdot Q} \frac{\partial w_{q i c \tau}}{\partial \eta_{r j c \tau}} d \eta_{r j c \tau}
$$

As for equation (2), this equation has two components. The first one is the between component and corresponds to the effect a shift-share approach measures. The second component captures the general equilibrum effects that are found when wages are determined by search and bargaining 
mechanisms and therefore, when a shift in employment composition spills over into wages in all occupations and industries of the city. Using equation (11), the total effect on the city's average wage can be arranged as

$$
\begin{aligned}
\Delta w_{c \tau} & =\sum_{j, r}^{I \cdot Q} w_{r j c(\tau-1)} \Delta \eta_{r j c \tau} \\
& +\beta_{1} \sum_{q}^{Q} \eta_{q c(\tau-1)} \sum_{j}^{I} \nu_{q j(\tau-1)} \Delta \eta_{j c \tau, q}+\beta_{2} \sum_{i}^{I} \eta_{i c(\tau-1)} \sum_{r}^{Q} \nu_{r i(\tau-1)} \Delta \eta_{r c \tau, i}+\beta_{3} \sum_{j, r}^{I \cdot Q} \nu_{r j(\tau-1)} \Delta \eta_{r j c \tau}
\end{aligned}
$$

where the first term correponds to the between component computed in a shift-share exercise and the last three terms to the general equilibrium effects stemming from search and bargaining. ${ }^{23}$ The terms $\sum_{j}^{I} \nu_{q j(\tau-1)} \Delta \eta_{j c \tau, q}, \sum_{r}^{Q} \nu_{r i(\tau-1)} \Delta \eta_{r c \tau, i}$ and $\sum_{j, r}^{I \cdot Q} \nu_{r j(\tau-1)} \Delta \eta_{r j c \tau}$ correspond to the between components of the industrial, occupational and city composition indices (as described for instance by equation (13)) and to the indices themselves in the case where the national wage premia remain constant.

One can compute the estimated total effect on the average wage of German cities using the estimated spillovers obtained in column 1 of Table 1 (and recalling that the estimate of $\beta_{3}$ is zero) together with observed occupation-industry-city wages, occupation-industry wage premia and observed change in employment shares. That is,

$$
\Delta w_{c \tau}=\underbrace{\sum_{j, r}^{I \cdot Q} w_{r j c(\tau-1)} \Delta \eta_{r j c \tau}}_{\text {shift-share }}+\underbrace{1.072 \sum_{q}^{Q} \eta_{q c(\tau-1)} \sum_{j}^{I} \nu_{q j(\tau-1)} \Delta \eta_{j c \tau, q}+2.75 \sum_{i}^{I} \eta_{i c(\tau-1)} \sum_{r}^{Q} \nu_{r i(\tau-1)} \Delta \eta_{r c \tau, i}}_{\text {General equilibrium effects }}
$$

$$
\begin{aligned}
& { }^{23} \text { In particular, } \\
& \begin{aligned}
\sum_{i, q}^{I \cdot Q} \frac{\partial w_{c \tau}}{\partial w_{q i c \tau}} \sum_{j, r}^{I \cdot Q} \frac{\partial w_{q i c \tau}}{\partial \eta_{r j c \tau}} d \eta_{r j c \tau} & =\sum_{i, q}^{I \cdot Q} \eta_{q i c(\tau-1)}\left[\sum_{j}^{I} \frac{\partial w_{q i c \tau}}{\partial \eta_{j c \tau, q}} d \eta_{j c \tau, q}+\sum_{r}^{Q} \frac{\partial w_{q i c \tau}}{\partial \eta_{r c \tau, i}} d \eta_{r c \tau, i}+\sum_{j, r}^{I \cdot Q} \frac{\partial w_{q i c \tau}}{\partial \eta_{r j c \tau}} d \eta_{r j c \tau}\right] \\
& =\sum_{i, q}^{I \cdot Q} \eta_{q i c(\tau-1)}\left[\sum_{j}^{I} \beta_{1} \nu_{q j \tau} d \eta_{j c \tau, q}+\sum_{r}^{Q} \beta_{2} \nu_{r i \tau} d \eta_{r c \tau, i}+\sum_{j, r}^{I \cdot Q} \nu_{r j \tau} d \eta_{r j c \tau}\right] \\
& =\beta_{1} \sum_{q}^{Q} \eta_{q c(\tau-1)} \sum_{j}^{I} \nu_{q j \tau} d \eta_{j c \tau, q}+\beta_{2} \sum_{i}^{I} \eta_{i c(\tau-1)} \sum_{r}^{Q} \nu_{r i \tau} d \eta_{r c \tau, i}+\beta_{3} \sum_{j, r}^{I \cdot Q} \nu_{r j \tau} d \eta_{r j c \tau}
\end{aligned}
\end{aligned}
$$

where $d \eta_{j c \tau, q}=\frac{\partial \eta_{j c \tau, q}}{\partial \eta_{q j c \tau}} d \eta_{q j c \tau}$ and $d \eta_{r c \tau, i}=\frac{\partial \eta_{r c \tau, i}}{\partial \eta_{r i c \tau}} d \eta_{r i c \tau}$. 
where the second term captures the spillover effects of a shift in the industrial composition of employment and the third component reflects the spillover effects associated with changes in occupational composition. This equation makes it clear that a shift-share approach misrepresents the total wage effects of a change in employment composition. Using the mean values of the composition indices in Table 3, equation (16) implies a total effect on cities' average wages of 2.8 times the effect that is predicted by a shift-share exercise.

Equation (16) can be used to evaluate how a shock at the national level spreads across local labour markets and affects city-level wages. For instance, the methodology could be used to assess the local labour market effects of increased exposure to Chinese competition in Germany. Imagine that one can isolate city-specific sectoral and occupational changes in employment shares that are due to increased trade exposure, perhaps using an index of import exposure as in Autor et al. (2013). One would then obtain an estimate of the change in cities' average wages that is due to increase exposure to Chinese competition by replacing changes in employment shares in equation (16) by the corresponding trade-induced changes.

\section{Concluding remarks}

This paper evaluates how one can best assess the effects of changes in both the industrial and occupational composition of employment on cities' average wages. This is an important question to properly evaluate the local labour market impacts of a shock, such as a trade or a technology shock, shifting the composition of employment across industries and/or occupations.

The paper argues that the traditionally-used shift-share approach can be misleading if changes in the industry or occupation mix in a labour market spill over into occupation-industry-city wages. This study first uses a search and bargaining model to illustrate how changes in employment composition can affect wages in all industries and occupations of a labour market. The paper then adopts an instrumental variables strategy to estimate the spillover effects of shifts in industrial and occupational composition in cities of Germany.

The approach taken in this paper differs from BGS in two aspects. First, this paper explores 
whether the search and bargaining forces found by BGS in the U.S. are also present in Germany. Second, BGS only focuses on changes in the industrial structure. This paper proposes to separate out the effects associated with shifts in both industrial and occupational composition. In addition, it examines whether an approach that only targets industries is itself biased due to the fact that changes in occupational structure are unlikely orthogonal to changes in the industry mix.

The findings are twofold. First, the estimated spillover effects are large and statistically significant, suggesting that shift-share likely misrepresents the total effects of a shock on cities' average wages. An approach which accounts for the potential general equilibrium effects that a compositional shift may have on occupation-industry-city wages implies a total effect on cities' average wages of 2.8 times the effect that is predicted by a shift-share methodology. Second, even if one is only interested in the wage effects associated with an industry-specific shock, accounting for both industrial and occupational adjustments simultaneously is crucial to identify these wage spillover effects. In particular, omitting inter-occupational labour adjustment produces a biased estimate of the sectoral wage spillover effects, due to the fact that adjustments along the occupational dimension are endogeneous to changes in the industry mix. 


\section{References}

D. Acemoglu. Technical Change, Inequality, and the Labor Market. Journal of Economic Literature, 40(1):7-72, 2002.

D. Acemoglu and J. Angrist. How Large Are Human-Capital Externalities? Evidence from Compulsory Schooling Laws. NBER Macroeconomics Annual, 15:9-59, 2000.

D. Acemoglu and D. Autor. Skills, Tasks and Technologies: Implications for Employment and Earnings. Handbook of Labor Economics, 4:1043-1171, 2011.

D. Autor, F. Levy, and R. Murnane. The Skill Content of Recent Technological Change: An Empirical Exploration. Quarterly Journal of Economics, 118(4):1279-1333, 2003.

D. Autor, L. Katz, and M. Kearney. The Polarization of the U.S. Labor Market. American Economic Review, 92(2):189-194, 2006.

D. Autor, D. Dorn, and G. Hanson. The China Syndrome: Local Labor Market Effects of Import Competition in the United States. American Economic Review, 103(6):2121-2168, 2013.

P. Beaudry, D. Green, and B. Sand. Does Industrial Composition Matter for Wages: An Empirical Evaluation Based on Search and Bargaining Theory. Econometrica, 80(3):1063-1104, 2012.

S. Bender, A. Haas, and C. Klose. IAB Employment Subsample 1975-1995: Opportunities for Analysis Provided by the Anonymised Subsample. IZA Discussion Paper Series, 2000.

O. J. Blanchard and L.F. Katz. Regional Evolutions. Brookings Papers on Economic Activity, 1: $1-76,1992$.

J. Bound and G. Johnson. Changes in the Structure of Wages in the 1980's: An Evaluation of Alternative Explanations. American Economic Review, 82:371-392, 1992.

C. Dustmann, J. Ludtseck, and U. Schoenberg. Revisiting the German Wage Structure. Quarterly Journal of Economics, 124(2):843-881, 2009. 
M. Goos and A. Manning. Lousy and Lovely Jobs: The Rising Polarization of Work in Britain. Review of Economics and Statistics, 89(1):118-133, 2007.

M. Goos, A. Manning, and A. Salomons. Job Polarization in Europe. American Economic Review: Papers and Proceedings, 99(2):58-63, 2009.

G. Kambourov and I. Manovskii. Occupational Specificity of Human Capital. International Economic Review, 50:63-115, 2009b.

L. Katz and D. Autor. Changes in the Wage Structure and Earnings Inequality. In Ashenfelter, O. and Card, D., Handbook of Labor Economics, 1999.

T. Lemieux. Decomposing Changes in Wage Distributions: A Unified Approach. Canadian Journal of Economics, 35(4):646-688, 2002.

E. Moretti. Estimating the Social Returns to Higher Education: Evidence from Longitudinal and Repeated Cross-Sectional Data. Journal of Econometrics, 121(1-2):175-212, 2004.

D. Parent. Industry-Specific Capital and the Wage Profile: Evidence from the National Longitudinal Survey of Youth and the Panel Study of Income Dynamics. Journal of Labor Economics, 18:306-323, 2000.

A. Spitz-Oener. Technical Change, Job Tasks, and Rising Educational Demands: Looking Outside the Wage Structure. Journal of Labor Economics, 24(2):235-270, 2006.

P. Sullivan. Empirical Evidence on Occupation and Industry Specific Human Capital. Labour Economics, 17:567-580, 2010.

J. Tschopp. Wage Formation: Towards Isolating Search and Bargaining Effects from the Marginal Product. Working paper, 2015. 


\section{Tables}

Table 1: Baseline specification.

\begin{tabular}{|c|c|c|}
\hline Dependent variable & $\Delta \log w_{q i c \tau}$ & $\Delta \log w_{i c \tau}$ \\
\hline Regressors & $\begin{array}{c}(\mathbf{1}) \\
\text { Baseline }\end{array}$ & $\begin{array}{c}\mathbf{( 2 )} \\
\text { Omitting } \\
\text { occupations }\end{array}$ \\
\hline$\Delta R_{q c \tau}^{I N D}$ & $\begin{array}{l}1.072^{* * *} \\
(0.271)\end{array}$ & \\
\hline$\Delta R_{i c \tau}^{O C C}$ & $\begin{array}{l}2.750^{* * *} \\
(0.533)\end{array}$ & \\
\hline$\Delta R_{c \tau}^{C I T Y}$ & $\begin{array}{c}0.647 \\
(1.140)\end{array}$ & \\
\hline$\Delta \tilde{R}_{c \tau}^{I N D}$ & & $\begin{array}{c}-0.189 \\
(1.149)\end{array}$ \\
\hline$\Delta E R_{c \tau}$ & $\begin{array}{c}0.281 \\
(0.410)\end{array}$ & $\begin{array}{c}0.415 \\
(0.580)\end{array}$ \\
\hline Implied $\varphi_{I N D}$ & 0.832 & \\
\hline Implied $\varphi_{O C C}$ & 0.576 & \\
\hline $\mathrm{H} 0: \beta_{1}=\beta_{2}$ & {$[0.000]$} & \\
\hline Baseline-implied $\tilde{\beta}_{1}$ & & 1.339 \\
\hline $\mathrm{H} 0: \tilde{\beta}_{1}=1$ & & {$[0.731]$} \\
\hline F-first stage: $\Delta R_{q c \tau}^{I N D}$ & 620 & 44 \\
\hline F-first stage: $\Delta R_{i c \tau}^{O C C}$ & 201 & \\
\hline F-first stage: $\Delta R_{c \tau}^{C I T Y}$ & 262 & \\
\hline F-first stage: $\Delta E R_{c \tau}$ & 22 & 50 \\
\hline Hansen & 0.22 & 0.41 \\
\hline Observations & 9376 & 1665 \\
\hline
\end{tabular}


Table 2: Additional controls.

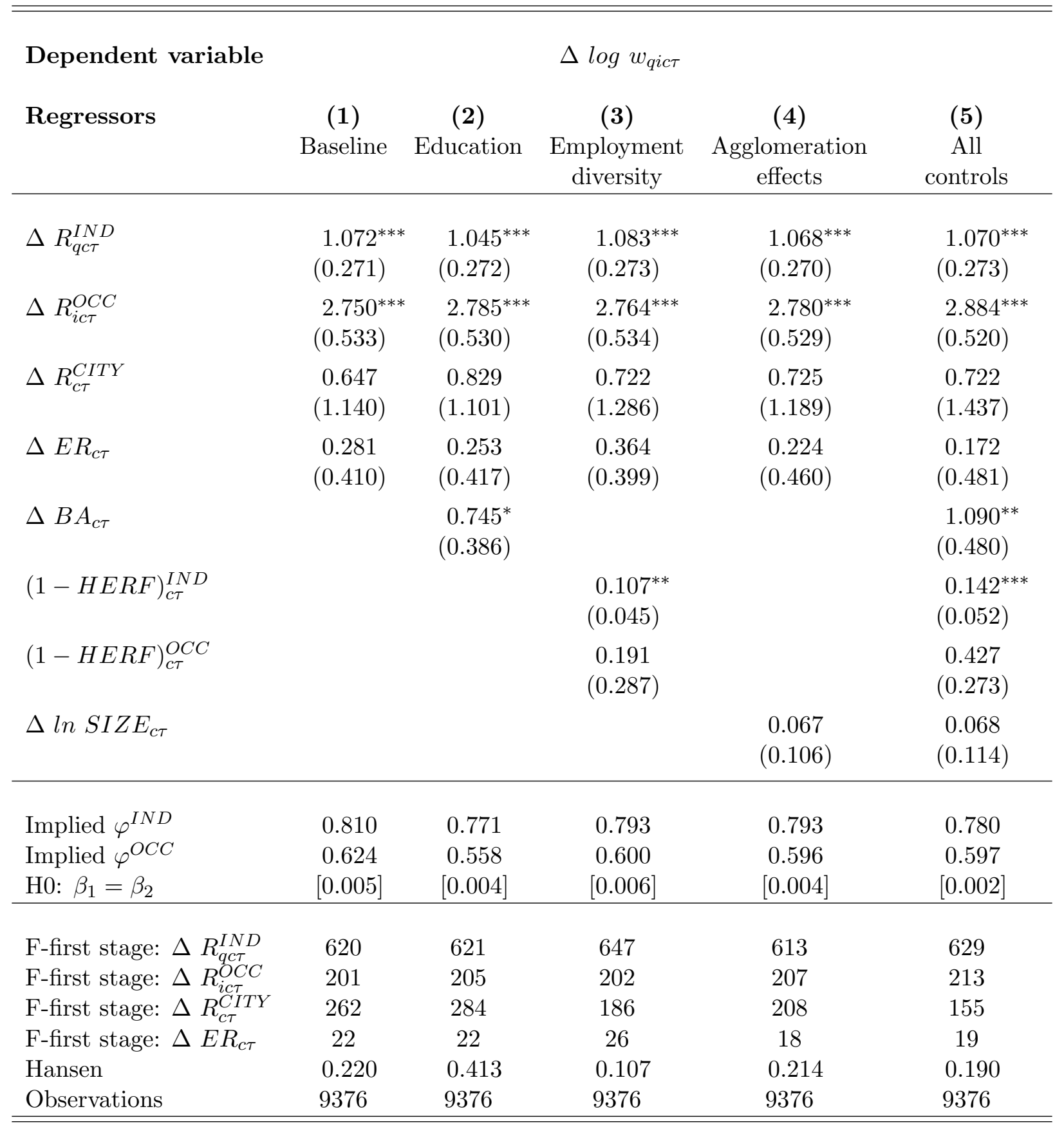

Notes: All estimations contain $d_{q i \tau}$. Standard errors are clustered at the city level. Standard errors in parentheses. *** $\mathrm{p}<0.01,{ }^{* *} \mathrm{p}<0.05,{ }^{*} \mathrm{p}<0.1$. $\mathrm{p}$-values in brackets. 
Table 3: Summary statistics: composition indices

\begin{tabular}{lcrrr}
\hline \hline Variable & Mean & Std. Dev. & Min. & Max. \\
\hline & & & & \\
$\sum_{r}^{Q} \eta_{r c(\tau-1)} \Delta R_{r c \tau}^{I N D}$ & 0.0009 & 0.0055 & -0.0101 & 0.0111 \\
$\sum_{j}^{I} \eta_{j c(\tau-1)} \Delta R_{j c \tau}^{O C C}$ & 0.0008 & 0.0056 & -0.0097 & 0.0122 \\
$\Delta \tilde{R}_{c}^{C I T Y}$ & 0.0012 & 0.0056 & -0.0105 & 0.0123 \\
\hline \hline
\end{tabular}

\section{Figures}

Figure 1: Evolution of industrial and occupational composition indices, averaged across cities of Western Germany, over the period 1980-2001.

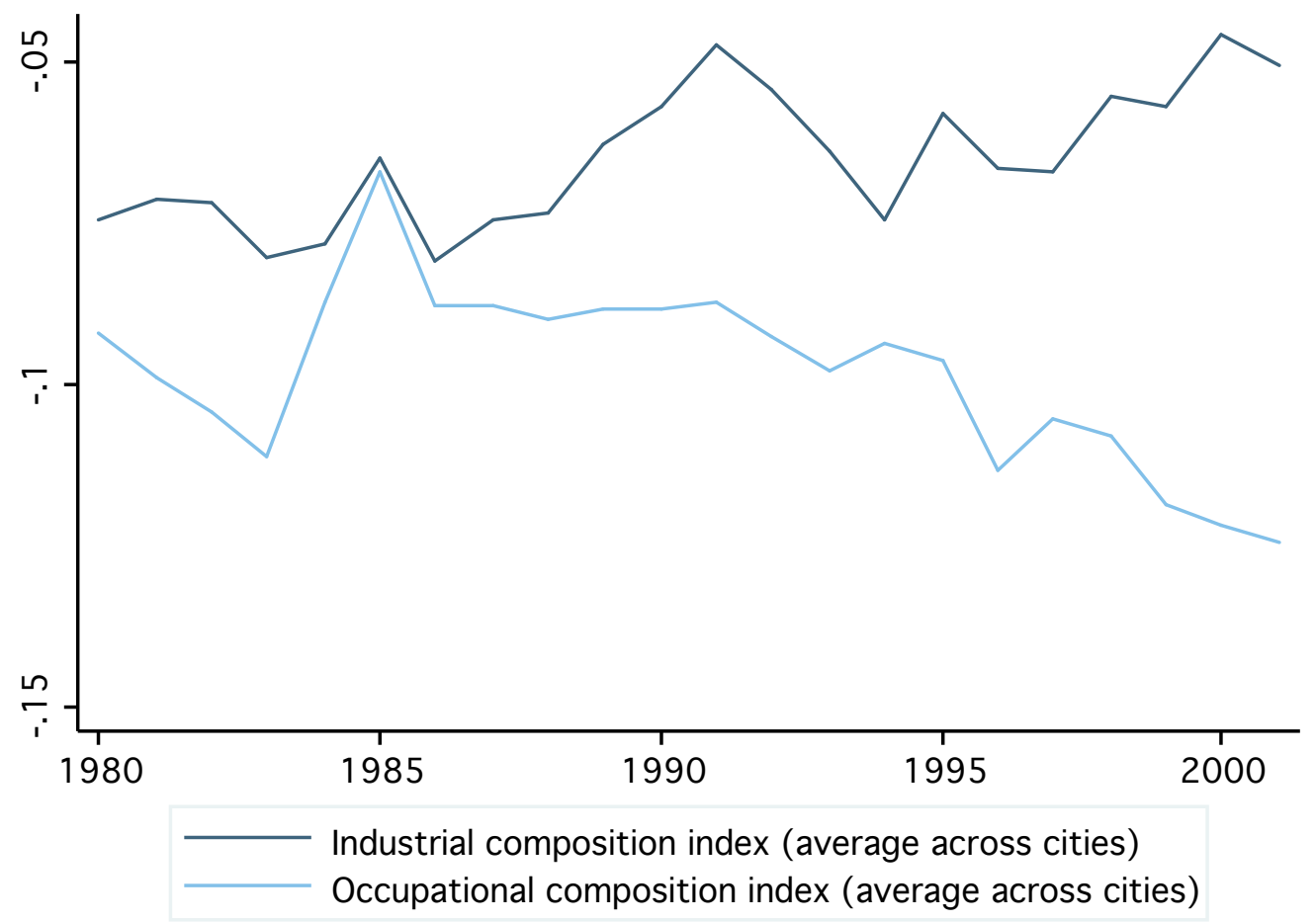

Note: The figure is constructed from the IAB anonymized sample. 


\section{Web Appendix}

The Wage Response to Shocks: The Role of Inter-Occupational

Labour Adjustment

Jeanne Tschopp*

June 2015

*Department of Economics, Ryerson University, 350 - Victoria St., Toronto, ON, Canada, M5B 2K3; jtschopp@economics.ryerson.ca. 


\section{A Mobility illustration in a two-by-two occupation-industry model}

Figure 1 illustrates mobility in a two-by-two occupation-industry model. Let $i$ and $j$ denote industry subscripts and $q$ and $r$ be occupation subscripts. $\varphi^{I N D} \varphi^{O C C}$ captures the importance of worker immobility outside an occupation-industry cell. Mobility within occupation across industries is represented by the horizontal arrow and captured by $\varphi^{I N D} \varphi^{O C C}$. The vertical arrow shows mobility within industry across occupations. This type of mobility is captured by $\varphi^{I N D}\left(1-\varphi^{O C C}\right)$. The importance of mobility across the entire industry-occupation matrix is captured by $\left(1-\varphi^{I N D}\right)(1-$ $\varphi^{O C C}$ ) and represented by the diagonal arrow. 
Figure 1: Mobility illustration in a two-by-two occupation-industry model.

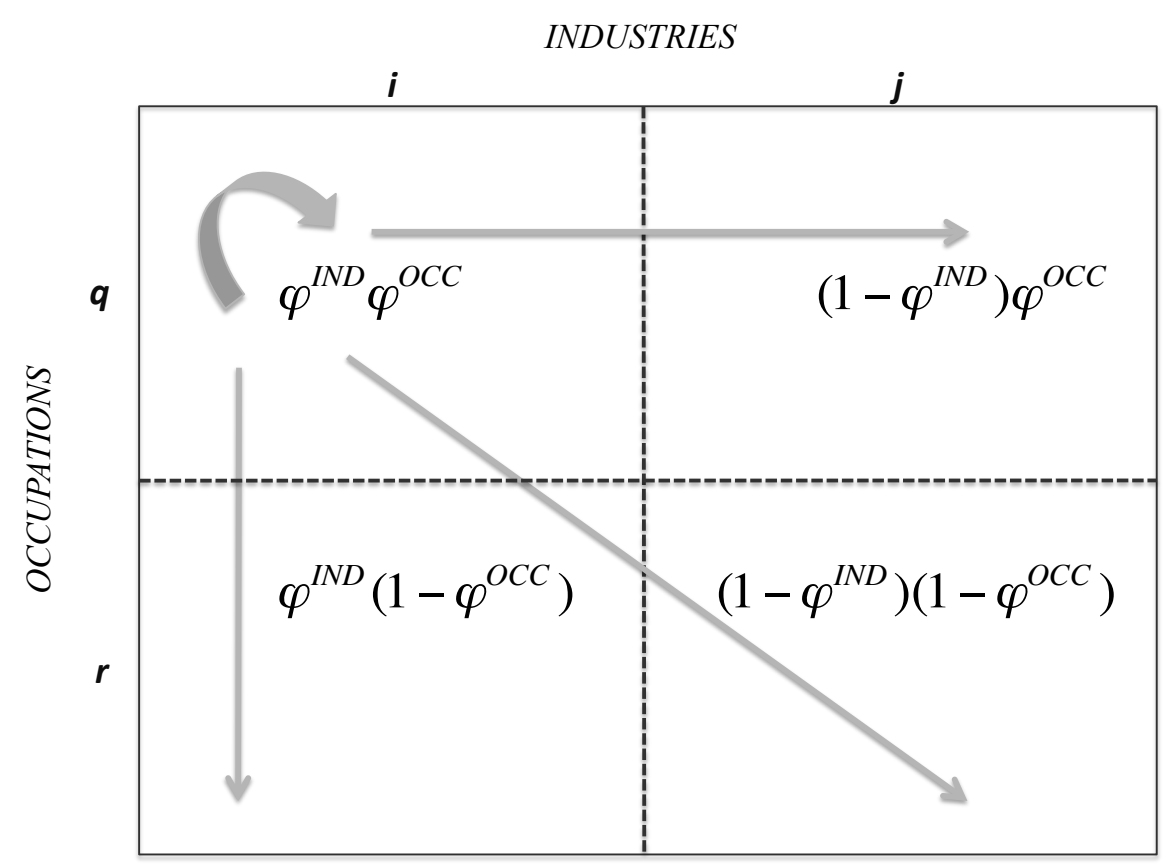




\section{B Stylized facts: worker mobility}

Figure 2 and Table 1 present evidence of inter-industry and inter-occupational worker mobility. Evidence is constructed on the basis of employed individuals who can be traced over two consecutive years. Inter-industry mobility is defined as the fraction of currently employed individuals who report a current industry different from the industry reported one year earlier. Inter-occupational mobility is defined equivalently.

Figure 2 shows the evolution of workers' mobility across industries within a particular occupation, across occupations within a particular industry and across both industries and occupations, as a share of employed workers. Table 1 presents the associated summary statistics. On average, $8.1 \%$ of workers move across industries and/or occupations from one year to the other. $2.9 \%$ of workers move across industries within a particular occupation, $2.5 \%$ move across occupations within a particular industry and $2.7 \%$ move across both industries and occupations. Inter-industry and inter-occupational worker mobility are on average $5.6 \%$ and $5.2 \%$, respectively. 
Figure 2: Evolution of worker mobility across industries within occupation, across occupations within industry and across both industries and occupations as a share of West-German employed workers over the period 1977-2001.

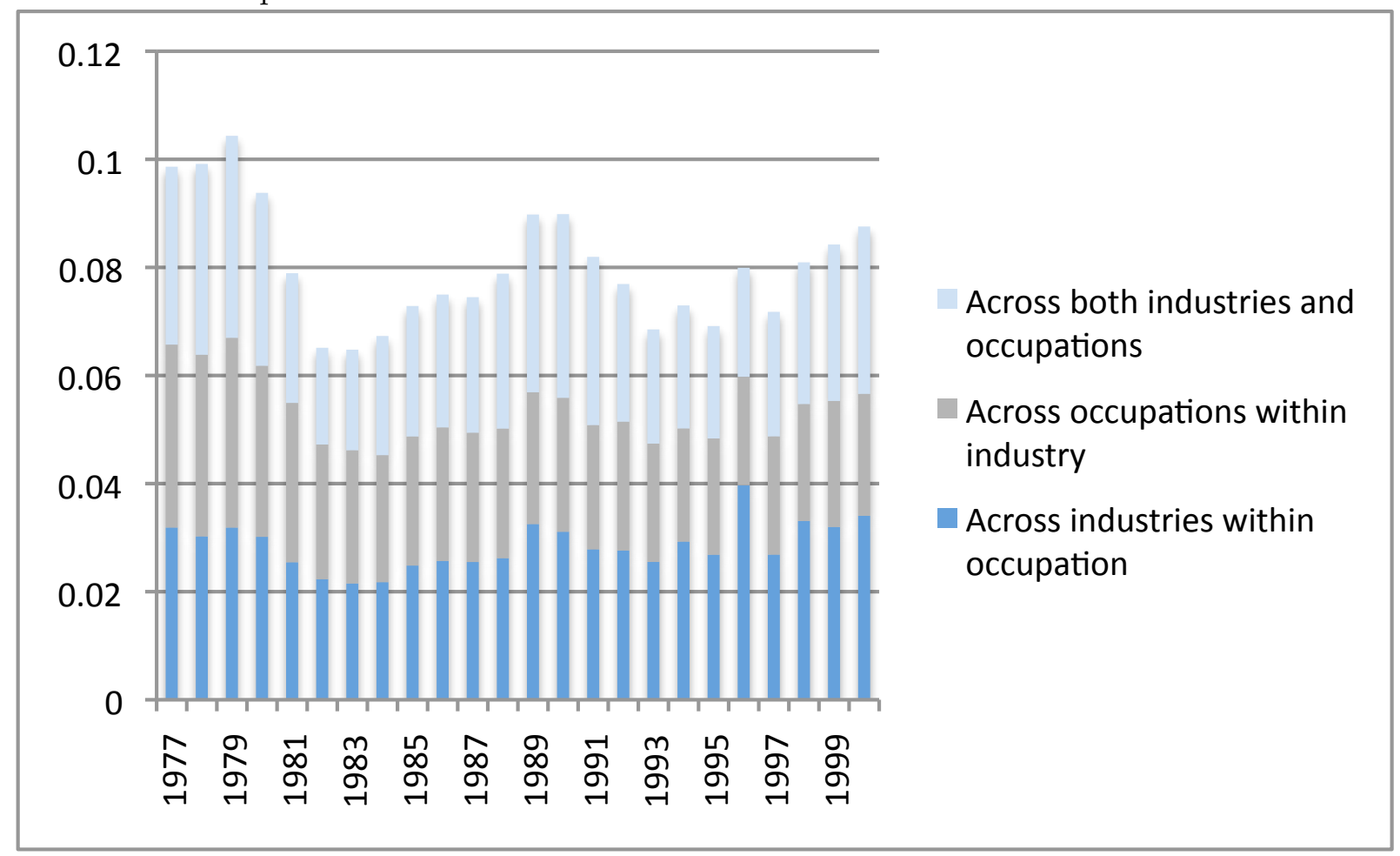


Table 1: Summary statistics (across years and cities): cross-industry and cross-occupational worker moves as a share of Western-German employed workers over the period 1977-2001.

\begin{tabular}{lcccc} 
Variable & Mean & Std. Dev. & Min. & Max. \\
\hline Share of employed workers who move: & & & & \\
Across industries within occupation & 0.029 & 0.004 & 0.022 & 0.040 \\
Across occupations within industry & 0.025 & 0.004 & 0.020 & 0.035 \\
Across both industries and occupations & 0.027 & 0.006 & 0.018 & 0.037 \\
& & & & \\
Mobility distribution: & & & & \\
Across industries within occupation & 0.356 & 0.042 & 0.305 & 0.497 \\
Across occupations within industry & 0.314 & 0.038 & 0.251 & 0.383 \\
Across both industries and occupations & 0.330 & 0.032 & 0.252 & 0.380
\end{tabular}

\section{Deriving the wage equation}

This section discusses how equation (11) can be derived from equation (10) in the manuscript. The model implies the following wage equation (equation 10 in the manuscript)

$$
\begin{aligned}
w_{q i c} & =\gamma_{1 c} \lambda_{q i c}+\gamma_{2 c}\left[\left(1-\varphi^{I N D}\right) \varphi^{O C C} \sum_{j}^{I} \eta_{j c, q} w_{q j c}\right. \\
& \left.+\varphi^{I N D}\left(1-\varphi^{O C C}\right) \sum_{r}^{Q} \eta_{r c, i} w_{r i c}+\left(1-\varphi^{I N D}\right)\left(1-\varphi^{O C C}\right) \sum_{j, r}^{I \cdot Q} \eta_{r j c} w_{r j c}\right]
\end{aligned}
$$

where $\lambda_{q i c}=p_{i} \theta_{q i c} \frac{Y_{i c}}{N_{q i c}}$ and the $\gamma^{\prime}$ 's are functions of the employment rate. ${ }^{1}$ Due to the strategic complementarity of occupation-industry-city wages, the parameters $\gamma_{2 c}\left(1-\varphi^{I N D}\right) \varphi^{O C C}, \gamma_{2 c} \varphi^{I N D}(1-$ $\left.\varphi^{O C C}\right)$ and $\gamma_{2 c}\left(1-\varphi^{I N D}\right)\left(1-\varphi^{O C C}\right)$ only capture partial spillover effects of a change in withinoccupation, within-industry or within-city employment, respectively. These partial effects depend

\footnotetext{
${ }^{1}$ In particular,

$$
\gamma_{1 c}=\frac{\left(\rho+\delta+\psi_{c} \varphi^{I N D} \varphi^{O C C}\right)}{\left[\left(\rho+\delta+\psi_{c} \varphi^{I N D} \varphi^{O C C}\right)+\kappa\left(\rho+\delta+\phi_{c}\right)\right]}
$$$$
\gamma_{2 c}=\frac{\left(\rho+\delta+\phi_{c}\right) \kappa}{\left[\left(\rho+\delta+\psi_{c} \varphi^{I N D} \varphi^{O C C}\right)+\kappa\left(\rho+\delta+\phi_{c}\right)\right]} \frac{\psi_{c}}{\left(\rho+\delta+\psi_{c}\right)},
$$

where $\phi_{c}$ and $\psi_{c}$ are functions of the employment rate. 
on city-specific employment rates (through $\gamma_{2 c}$ ), which are themselves determined endogenously. In order to obtain the total spillover effects, the paper first solves equation (1) for wages. The paper then uses a first-order log-linear approximation to explicate the relationship between occupationindustry-city wages and the employment rate. Solving equation (1) for wages, one obtains

$$
\begin{aligned}
w_{q i c} & =\gamma_{c 1} \lambda_{q i c}+\frac{\gamma_{1 c} \gamma_{2 c}}{1-\gamma_{2 c}\left(1-\varphi^{I N D} \varphi^{O C C}\right)}\left[\left(1-\varphi^{I N D}\right) \varphi^{O C C} \sum_{j}^{I} \eta_{j c, q} \lambda_{q j c}\right. \\
& \left.+\varphi^{I N D}\left(1-\varphi^{O C C}\right) \sum_{r}^{Q} \eta_{r c, i} \lambda_{r i c}+\left(1-\varphi^{I N D}\right)\left(1-\varphi^{O C C}\right) \sum_{j, r}^{I \cdot Q} \eta_{r j c} \lambda_{r j c}\right] .
\end{aligned}
$$

In order to explicitly express the employment rate, the paper takes a log-linear approximation around the point where cities have an identical structure of employment. This occurs when the technology parameter $\theta_{q i c}$ and the productivity shifter $A_{i c}$ are city-invariant, i.e. $\theta_{q i c}=\theta_{q i}$ and $A_{i c}=A_{i}$ (which implies $\eta_{i c, q}=\eta_{i, q}, \eta_{q c, i}=\eta_{q, i}, \eta_{q i c}=\eta_{q i}$ and $E R_{c}=E R$ ). Define $\hat{\theta}_{q i c}=\theta_{q i c}-\theta_{q i}$, the occupation-industry-specific relative advantage component in the technology for city $c$, such that $\sum_{c} \hat{\theta}_{q i c}=0$. Similarly, define $\hat{A}_{i c}=A_{i c}-A_{i}$, the industry-specific relative advantage component in the productivity for city $c$, such that $\sum_{c} \hat{A}_{i c}=0$. By definition, the structure of employment across industries and occupations is identical across cities (i.e. $\theta_{q i c}=\theta_{q i}$ and $A_{i c}=A_{i}$ ) when the relative advantage components $\hat{\theta}_{q i c}$ and $\hat{A}_{i c}$ are zero. Approximating equation (2) around the points where $\hat{\theta}_{q i c}=0, \hat{A}_{i c}=0$, and $\eta_{i c, q}=\eta_{i, q}, \eta_{q c, i}=\eta_{q, i}, \eta_{q i c}=\eta_{q i}, E R_{c}=E R$, one obtains

$$
\begin{aligned}
w_{q i c} & =\gamma_{1} \lambda_{q i}-f_{q i} E R+f_{q i} E R_{c}+\frac{\gamma_{1} \gamma_{2}}{1-\gamma_{2}\left(1-\varphi^{I N D} \varphi^{O C C}\right)}\left[\left(1-\varphi^{I N D}\right) \varphi^{O C C} \sum_{j}^{I} \eta_{j c, q} \lambda_{q j}\right. \\
& \left.+\varphi^{I N D}\left(1-\varphi^{O C C}\right) \sum_{r}^{Q} \eta_{r c, i} \lambda_{r i}+\left(1-\varphi^{I N D}\right)\left(1-\varphi^{O C C}\right) \sum_{j, r}^{I \cdot Q} \eta_{r j c} \lambda_{r j}\right]+\xi_{q i c}
\end{aligned}
$$

where the terms $\lambda_{q i}, E R, \gamma_{1}$ and $\gamma_{2}$ are $\lambda_{q i c}, E R_{c}, \gamma_{1 c}$ and $\gamma_{2 c}$ evaluated at $\hat{\theta}_{q i c}=0$ and $\hat{A}_{i c}=0$, respectively. The occupation-industry-specific term $f_{q i}$ is obtained from the linear approximation and is a function of the following set of parameters: $\gamma_{1}, \gamma_{2}, \varphi^{I N D}, \varphi^{O C C}$ and $\lambda_{q i}$. The term $\xi_{q i c}$ is obtained from the linear approximation as well and corresponds to the error term in the empirical 
section. In particular, $\xi_{q i c}$ depends on the relative advantage components $\hat{\theta}_{q i c}$ and $\hat{A}_{i c}$, i.e.

$$
\begin{aligned}
\xi_{q i c} & =\gamma_{1}\left(g_{q i} \hat{\theta}_{q i c}+h_{q i} \hat{A}_{i c}\right) \\
& +\frac{\gamma_{1} \gamma_{2}}{1-\gamma_{2}\left(1-\varphi^{I N D} \varphi^{O C C}\right)}\left[\left(1-\varphi^{I N D}\right) \varphi^{O C C} \sum_{j}^{I} \eta_{j, q}\left(g_{q j} \hat{\theta}_{q j c}+h_{q j} \hat{A}_{j c}\right)\right. \\
& +\varphi^{I N D}\left(1-\varphi^{O C C}\right) \sum_{r}^{Q} \eta_{r, i}\left(g_{r i} \hat{\theta}_{r i c}+h_{r i} \hat{A}_{i c}\right) \\
& \left.+\left(1-\varphi^{I N D}\right)\left(1-\varphi^{O C C}\right) \sum_{j, r}^{I \cdot Q} \eta_{r j}\left(g_{r j} \hat{\theta}_{r j c}+h_{r j} \hat{A}_{j c}\right)\right],
\end{aligned}
$$

where $\eta_{r, i}, \eta_{j, q}$ and $\eta_{r j}$ are respectively $\eta_{r c, i}, \eta_{j c, q}$ and $\eta_{r j c}$ evaluated at $\hat{\theta}_{q i c}=0$ and $\hat{A}_{i c}=0$. The occupation-industry-specific terms $g_{q i}$ and $h_{q i}$ are obtained from the linear approximation and are functions of the parameters $\gamma_{1}, \gamma_{2}, \varphi^{I N D}, \varphi^{O C C}$ and $\lambda_{q i}$.

The last step to obtain equation (11) in the manuscript consists in expressing $\lambda_{q i}$ as a function of the national occupation-industry wage premia. To do so, note that $w_{\text {qic }}$ approximated around the point where $\hat{\theta}_{q i c}=0, \hat{A}_{i c}=0$, and $\eta_{i c, q}=\eta_{i, q}, \eta_{q c, i}=\eta_{q, i}, \eta_{q i c}=\eta_{q i}$ satisfies:

$$
\begin{aligned}
& \left(w_{q i c}-w_{1 i c}\right)-\left(w_{q 1 c}-w_{11 c}\right) \\
& =\gamma_{1}\left[\left(\lambda_{q i}-\lambda_{1 i}\right)-\left(\lambda_{q 1}-\lambda_{11}\right)\right] \\
& +\gamma_{1}\left[\left(\xi_{q i c}-\xi_{1 i}\right)-\left(\xi_{q 1}-\xi_{11}\right)\right] \\
& +\gamma_{1}\left[\left(f_{q i}\left[\hat{\theta}_{q i c}+\hat{A}_{q i c}\right]-f_{1 i}\left[\hat{\theta}_{1 i c}+\hat{A}_{1 i c}\right]\right)-\left(f_{q 1}\left[\hat{\theta}_{q 1 c}+\hat{A}_{q 1 c}\right]-f_{11}\left[\hat{\theta}_{11 c}+\hat{A}_{11 c}\right]\right)\right],
\end{aligned}
$$

such that

$$
\sum_{c}^{C}\left(w_{q i c}-w_{1 i c}\right)-\left(w_{q 1 c}-w_{11 c}\right)=\gamma_{1}\left[\left(\lambda_{q i}-\lambda_{1 i}\right)-\left(\lambda_{q 1}-\lambda_{11}\right)\right]
$$

Define $\nu_{q i}=\left(w_{q i}-w_{11}\right)$, the national occupation-industry wage premium relative some numeraire occupation and industry and let $w_{q i}$ be the national occupation-industry average wage. One can then use equation (5) to obtain

$$
\nu_{q i}=\gamma_{1}\left(\lambda_{q i}-\lambda_{11}\right) .
$$


Equation (6) suggests that the national occupation-industry wage premium is positively related to both the price of the intermediate good $i$ and the marginal product of type- $q$ labour in industry $i$.

Substituting (6) into (3) and adding the time subscript, the wage equation can be rewritten as

$$
\begin{aligned}
w_{q i c \tau} & =\frac{\gamma_{1} \gamma_{2}\left(1-\varphi^{I N D} \varphi^{O C C}\right)}{1-\gamma_{2}\left(1-\varphi^{I N D} \varphi^{O C C}\right)} \lambda_{11 \tau}+\gamma_{1} \lambda_{q i \tau}+f_{q i} E R_{c \tau} \\
& +\frac{\gamma_{2}}{1-\gamma_{2}\left(1-\varphi^{I N D} \varphi^{O C C}\right)}\left[\left(1-\varphi^{I N D}\right) \varphi^{O C C} \sum_{j}^{I} \eta_{j c \tau, q} \nu_{q j \tau}+\varphi^{I N D}\left(1-\varphi^{O C C}\right) \sum_{r}^{Q} \eta_{r c \tau, i} \nu_{r i \tau}\right. \\
& \left.+\left(1-\varphi^{I N D}\right)\left(1-\varphi^{O C C}\right) \sum_{j, r}^{I \cdot Q} \eta_{r j c \tau} \nu_{r j \tau}\right]+\xi_{q i c \tau}
\end{aligned}
$$

Equation 11 in the manuscript is obtained by taking the first-difference with respect to time. Letting $\Delta$ denote a first difference, equation (7) becomes

$$
\Delta w_{q i c \tau}=\Delta d_{q i \tau}+\beta_{1} \Delta R_{q c \tau}^{I N D}+\beta_{2} \Delta R_{i c \tau}^{O C C}+\beta_{3} \Delta R_{c \tau}^{C I T Y}+f_{q i} \Delta E R_{c \tau}+\Delta \xi_{q i c \tau},
$$

where $f_{q i}>0$ and

$$
\begin{aligned}
d_{q i \tau} & =\frac{\gamma_{1} \gamma_{2}\left(1-\varphi^{I N D} \varphi^{O C C}\right)}{1-\gamma_{2}\left(1-\varphi^{I N D} \varphi^{O C C}\right)} \lambda_{11 \tau}+\gamma_{1} \lambda_{q i \tau} \\
R_{q c \tau}^{I N D} & =\sum_{j}^{I} \eta_{j c \tau, q} \nu_{q j \tau} \\
R_{i c \tau}^{O C C} & =\sum_{r}^{Q} \eta_{r c \tau, i} \nu_{r i \tau} \\
R_{c \tau}^{C I T Y} & =\sum_{j, r}^{I \cdot Q} \eta_{r j c \tau} \nu_{r j \tau}
\end{aligned}
$$

and

$$
\begin{aligned}
& \beta_{1}=\frac{\gamma_{2}}{1-\gamma_{2}\left(1-\varphi^{I N D} \varphi^{O C C}\right)}\left(1-\varphi^{I N D}\right) \varphi^{O C C} \geq 0 \\
& \beta_{2}=\frac{\gamma_{2}}{1-\gamma_{2}\left(1-\varphi^{I N D} \varphi^{O C C}\right)} \varphi^{I N D}\left(1-\varphi^{O C C}\right) \geq 0 \\
& \beta_{3}=\frac{\gamma_{2}}{1-\gamma_{2}\left(1-\varphi^{I N D} \varphi^{O C C}\right)}\left(1-\varphi^{I N D}\right)\left(1-\varphi^{O C C}\right) \geq 0 .
\end{aligned}
$$




\section{Implications of worker mobility across cities}

Worker mobility across cities can be modelled as either random or directed search across cities. In what follows, the paper first extends the model to allow for random search across cities. This extension modifies the value of being unemployed to a worker. Assume that with probability $(1-\Gamma)$ an unemployed worker gets a random job draw from his or her city, while with probability $\Gamma$ he or she gets a random job draw from any city. Letting $U_{q i c \tau}^{u^{\prime}}$ be the extended version of $U_{\text {qic }}^{u}$ under random search, ones obtains

$$
\begin{aligned}
\rho U_{q i c \tau}^{u^{\prime}} & =(1-\Gamma) U_{q i c \tau}^{u}+\Gamma[\varphi^{I N D} \varphi^{O C C} \underbrace{\sum_{c}^{C} \frac{N_{q i c}}{N_{q i}} U_{q i c \tau}^{e}}_{q i \tau \text {-specific term }}+\left(1-\varphi^{I N D}\right) \varphi^{O C C} \underbrace{\varphi^{I N D}\left(1-\varphi^{O C C}\right) \underbrace{\sum_{c}^{C} \sum_{r}^{Q} \frac{N_{r i c \tau}}{N_{r \tau}} U_{r i c \tau}^{e}}_{i \tau \text {-specific term }}+\left(1-\varphi^{I N D}\right)\left(1-\varphi^{O C C}\right) \underbrace{\sum_{c}^{C} \sum_{j, r}^{I \cdot Q} \frac{N_{r j c \tau}}{N \tau} U_{r j c}^{e}}_{\tau \text {-specific term }}-U_{q i c}^{u^{\prime}}]}_{\underbrace{\sum_{c}} \sum_{j}^{C} \frac{\sum_{j} \frac{N_{q j c \tau}}{N_{j \tau}} U_{q j c \tau}^{e}}{e}},
\end{aligned}
$$

where $N_{q i \tau}, N_{q \tau}$ and $N_{i \tau}$ denote occupation-industry, occupation and industry national employment, respectively, and where $N_{\tau}$ denotes the national employment at time $\tau$. Equation (9) suggests that allowing for random search across cities implies adding four terms to the wage equation: a $q i \tau$-specific, a $q \tau$-specific, a $i \tau$-specific and a time effect. Since these terms do not vary across cities and given that the baseline equation includes occupation-industry time-varying dummies, this extension has no impact on the estimates.

Directed search across cities can be modelled as follows. Assume that with probability $(1-\Lambda)$, an unemployed worker cannot move across cities. With probability $\Lambda$ he or she has the option to move to another city and chooses the city, indexed by $c^{\prime}$, that maximizes his or her value of finding a job relative to being unemployed. Let $U_{\text {qic } \tau}^{u *}$ be the extended version of $U_{\text {qic }}^{u}$ under directed search. The discounted value of being unemployed is given by

$$
\rho U_{q i c \tau}^{u *}=(1-\Lambda) U_{q i c \tau}^{u}+\Lambda \max _{c^{\prime}}[\underbrace{\sum_{j, r}^{I \cdot Q} \eta_{r i c^{\prime} \tau} U_{q i c^{\prime} \tau}^{u}}_{c^{\prime} \tau \text {-specific term }}-U_{q i c \tau}^{u *}] .
$$

Thus, allowing for directed search across cities implies adding a time-varying term to the wage equation. This has no incidence on the estimated coefficients since this term is captured by time fixed effects in the baseline specification. 


\section{E Inconsistency of OLS}

This section shows why OLS leads to inconsistent estimates of $\beta_{1}-\beta_{3}$ and of the coefficient on the employment rate. In what follows, the paper focuses on the city composition index. Proofs for the other composition indices and for the employment rate are completely symmetric.

Consistency of OLS requires that

$$
\lim _{I, Q, C \rightarrow \infty} \frac{1}{I} \frac{1}{Q} \frac{1}{C} \sum_{i}^{I} \sum_{q}^{Q} \sum_{c}^{C} \Delta R_{c \tau}^{C I T Y} \Delta \xi_{q i c \tau}=0
$$

where the city composition index can be decomposed in a "between" and a "within" component

$$
\Delta R_{c \tau}^{C I T Y}=\underbrace{\sum_{j, r}^{I \cdot Q} \nu_{r j(\tau-1)} \Delta \eta_{r j c \tau}}_{\text {Between component }}+\underbrace{\sum_{j, r}^{I \cdot Q} \eta_{r j c \tau} \Delta \nu_{r j \tau}}_{\text {Within component }}
$$

and where the error term is given by

$$
\begin{aligned}
\xi_{q i c \tau} & =\gamma_{1}\left(g_{q i} \hat{\theta}_{q i c \tau}+h_{q i} \hat{A}_{i c \tau}\right) \\
& +\frac{\gamma_{1} \gamma_{2}}{1-\gamma_{2}\left(1-\varphi^{I N D} \varphi^{O C C}\right)}\left[\left(1-\varphi^{I N D}\right) \varphi^{O C C} \sum_{j}^{I} \eta_{j, q}\left(g_{q j} \hat{\theta}_{q j c \tau}+h_{q j} \hat{A}_{j c \tau}\right)\right. \\
& +\varphi^{I N D}\left(1-\varphi^{O C C}\right) \sum_{r}^{Q} \eta_{r, i}\left(g_{r i} \hat{\theta}_{r i c \tau}+h_{r i} \hat{A}_{i c \tau}\right) \\
& \left.+\left(1-\varphi^{I N D}\right)\left(1-\varphi^{O C C}\right) \sum_{j, r}^{I \cdot Q} \eta_{r j}\left(g_{r j} \hat{\theta}_{r j c \tau}+h_{r j} \hat{A}_{j c \tau}\right)\right]
\end{aligned}
$$

Substituting equation (11) into (10), the consistency condition can be rewritten as

$$
\begin{aligned}
\lim _{I, Q, C \rightarrow \infty} \frac{1}{I} \frac{1}{Q} & \frac{1}{C}\left[\sum_{j}^{I} \sum_{r}^{Q} \nu_{r j(\tau-1)} \sum_{c}^{C} \Delta \eta_{r j c \tau} \sum_{i}^{I} \sum_{q}^{Q} \Delta \xi_{q i c \tau}\right. \\
& \left.+\sum_{j}^{I} \sum_{r}^{Q} \Delta \nu_{r j \tau} \sum_{c}^{C} \eta_{r j c \tau} \sum_{i} \sum_{q} \Delta \xi_{q i c \tau}\right]=0
\end{aligned}
$$


which is equivalent to requiring that the following two conditions be satisfied

$$
\lim _{I, Q, C \rightarrow \infty} \frac{1}{I} \frac{1}{Q} \frac{1}{C} \sum_{c}^{C}\left[\Delta \eta_{r j c \tau} \sum_{i}^{I} \sum_{q}^{Q} \Delta \xi_{q i c \tau}\right]=0
$$

and

$$
\lim _{I, Q, C \rightarrow \infty} \frac{1}{I} \frac{1}{Q} \frac{1}{C} \sum_{c}^{C}\left[\eta_{r j c \tau} \sum_{i}^{I} \sum_{q}^{Q} \Delta \xi_{q i c \tau}\right]=0
$$

However, these two conditions cannot be satisfied as the employment shares are correlated with the error term. This can be seen directly by noting that $\eta_{q i c \tau}$, approximated around the point where $\hat{\theta}_{\text {qic } \tau}=0$ and $\hat{A}_{i c \tau}=0$, is given by

$$
\begin{aligned}
\eta_{q i c \tau}=\frac{1}{I Q} & +\pi_{1}\left[g_{q i} \hat{\theta}_{q i c \tau}+h_{q i} \hat{A}_{i c \tau}\right] \\
& +\pi_{2} \sum_{r}^{Q} \eta_{r, i}\left[g_{r i} \hat{\theta}_{r i c \tau}+h_{r i} \hat{A}_{i c \tau}\right] \\
& +\pi_{3} \sum_{j}^{I} \eta_{j, q}\left[g_{q j} \hat{\theta}_{q j c \tau}+h_{q j} \hat{A}_{i c \tau}\right] \\
& +\pi_{4} \sum_{j, r}^{I \cdot Q} \eta_{r j}\left[g_{r j} \hat{\theta}_{r j c \tau}+h_{r j} \hat{A}_{j c \tau}\right],
\end{aligned}
$$

where the $\pi_{1}-\pi_{4}$ are occupation-industry-specific constant terms obtained from the linear approximation.

The paper proposes to use the following instruments

$$
I V^{C I T Y, B E T W E E N}=\sum_{j, r}^{I \cdot Q} \nu_{r j(\tau-1)} \Delta \hat{\eta}_{r j c \tau} \quad \text { and } \quad I V^{C I T Y, W I T H I N}=\sum_{j, r}^{I \cdot Q} \hat{\eta}_{r j c \tau} \Delta \nu_{r j \tau}
$$

where $\hat{\eta}_{r j c \tau}$ is predicted employment in a particular $r j c$ cell as a share of city $c$ predicted employment. The conditions ensuring the validity of these instruments is similar to (13) and (14) but use predicted employment shares in place of actual employment shares. Specifically, these conditions 
are

$$
\lim _{I, Q, C \rightarrow \infty} \frac{1}{I} \frac{1}{Q} \frac{1}{C} \sum_{c}^{C}\left[\Delta \hat{\eta}_{r j c \tau} \sum_{i}^{I} \sum_{q}^{Q} \Delta \xi_{q i c \tau}\right]=0
$$

and

$$
\lim _{I, Q, C \rightarrow \infty} \frac{1}{I} \frac{1}{Q} \frac{1}{C} \sum_{c}^{C}\left[\hat{\eta}_{r j c \tau} \sum_{i}^{I} \sum_{q}^{Q} \Delta \xi_{q i c \tau}\right]=0 .
$$

Since predicted employment shares are constructed using start-of-period occupation-industry-city employment, these conditions require that past and changes in past occupation-industry-city employment is uncorrelated with future shocks to the city-specific productivity components that are left in the error term. 


\section{F Industries, occupations and cities}

Table 1: Industrial classification, 16 categories.

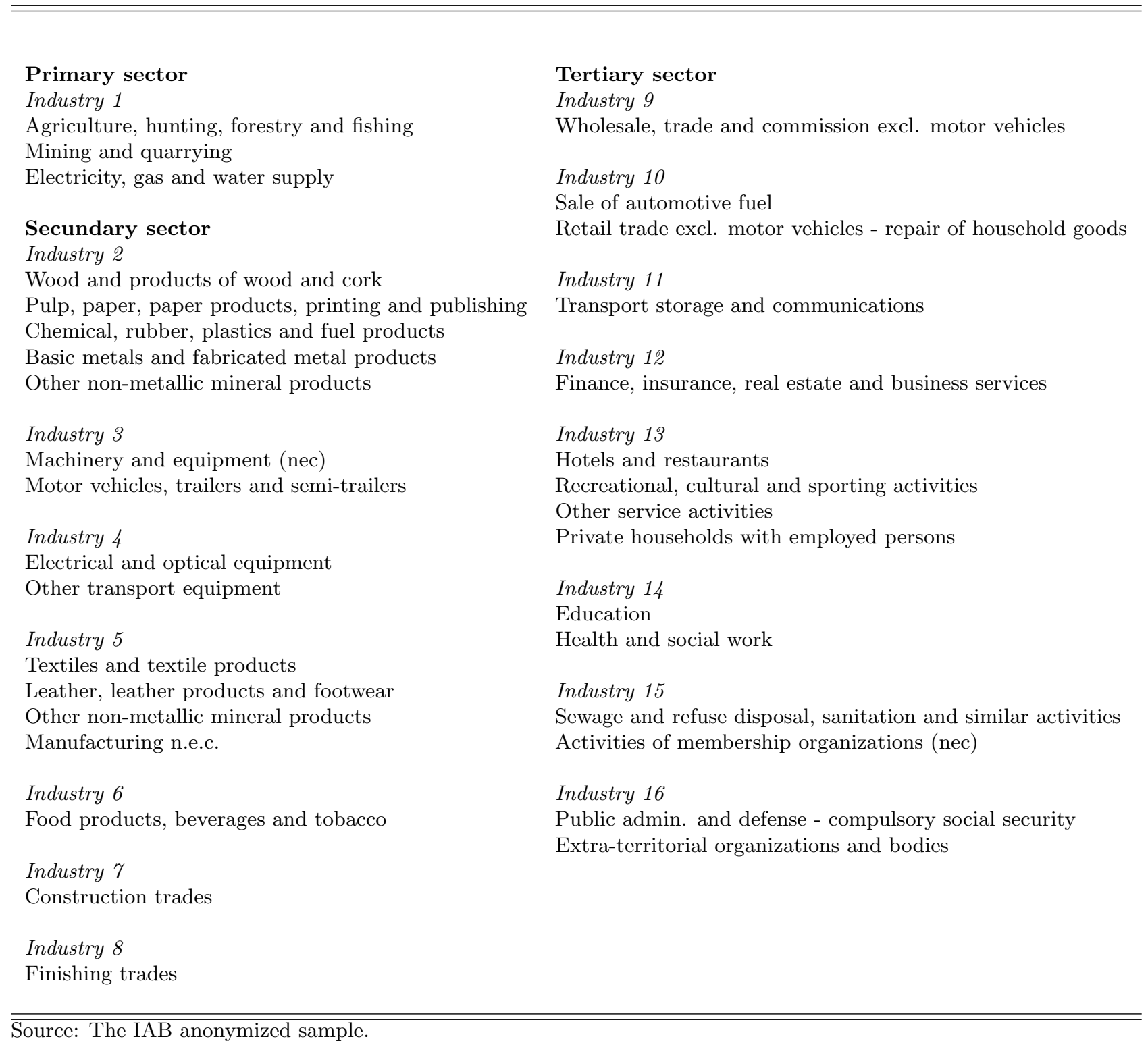


Table 2: Occupational classification, 33 categories.

\section{Agricultural}

Farming, forestry, gardening, fishing

Mining and quarrywork

Mining and quarrywork

\section{Manufacturing}

Stone, jewelery, brickwork

Glass and ceramics

Chemicals, plastics and rubber

Paper and printing

Woodwork

Metalworkers, primary product

Skilled metal work and related

Electrical

Metal and assembly / installation

Textiles

Leather goods

Food, drink and tobacco

Construction

Building

Carpenters

\section{Painters}

Goods sorters, packagers

Assistants

Machine operators

\section{Technicians}

Technicians - engineers and related

Technicians - manufacturing and science

\section{Services and professionals}

Buying and selling

Banking, insurance, agents

Arts, creative and recreational

Other services, personal and leisure services

Travel and transport

Administration and bureaucracy

Public order, safety and security

Health services

Teaching and social employment

Other

Other occupations

Source: The IAB anonymized sample. 
Table 3: Urban centers of the local labour markets, except for areas with more than one urban center (marked with a ${ }^{*}$ ).

\begin{tabular}{ll}
\hline \hline & \\
Aarchen & Münster \\
Augsburg & Nürnberg-Fürth-Erlangen \\
Bielefeld & Oldenburg \\
Braunschweig-Salzgitter & Osnabrück \\
Bremen & Paderborn \\
Bremerhaven & Pforzheim \\
Freiburg im Breisgau & Regensburg \\
Göttingen & Region Hannover \\
Hamburg & Rhein-Main* \\
Heilbronn & Rhein-Neckar* \\
Hildesheim & Rheinschiene* \\
Ingolstadt & Ruhr* \\
Kaiserlautern & Siegen \\
Karlsruhe & Saarbrücken \\
Kassel & Stuttgart-Reutlingen \\
Kiel & Trier-Saarburg and KS Trier \\
Koblenz & Ulm \\
Lübeck & Wolfsburg and Helmstadt \\
München & Wüzburg \\
\hline \hline
\end{tabular}

Note: Local labour markets are defined by commuting areas according to the Federal Office for Building and Regional Planning. 
G Other industrial and occupational classifications 


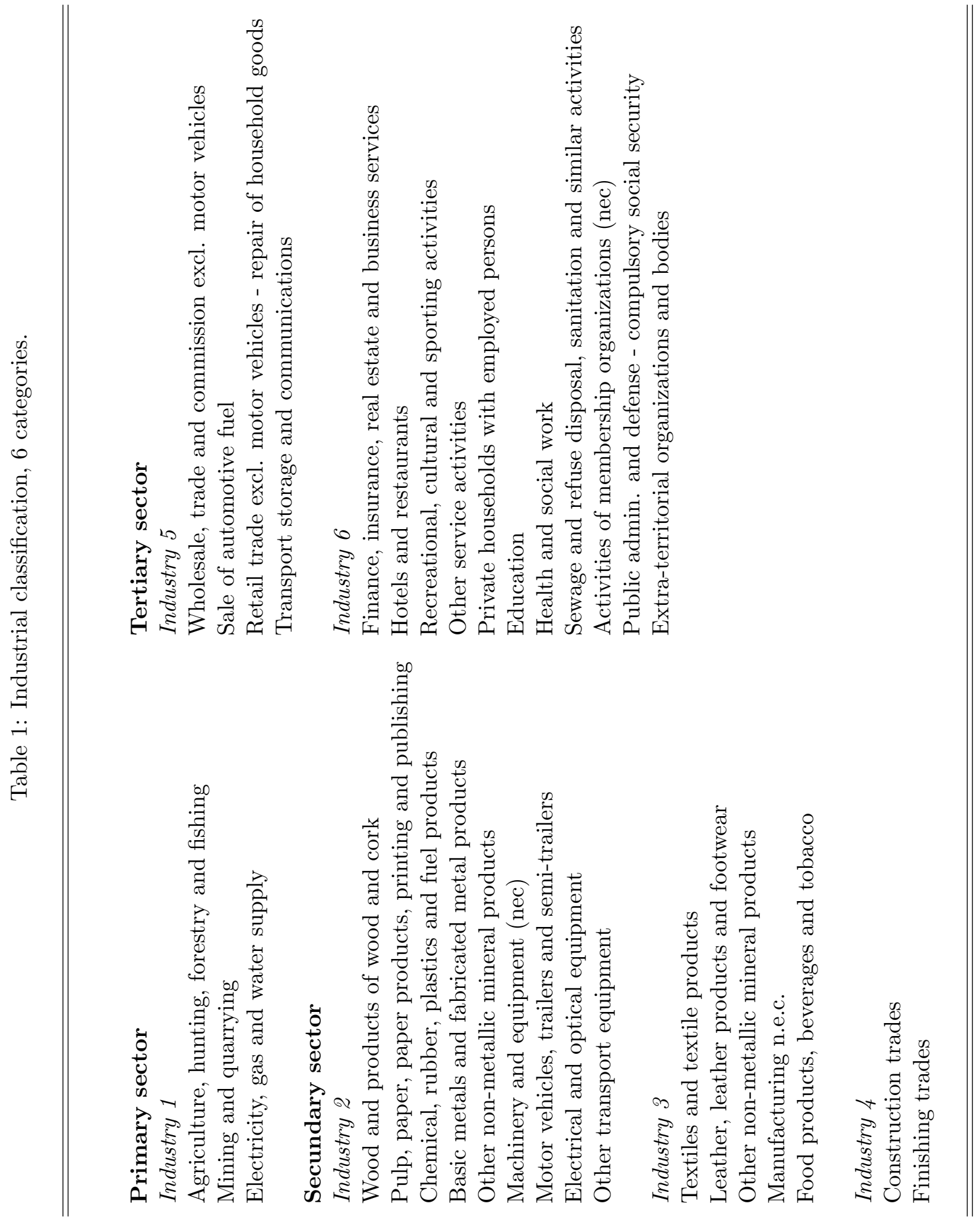




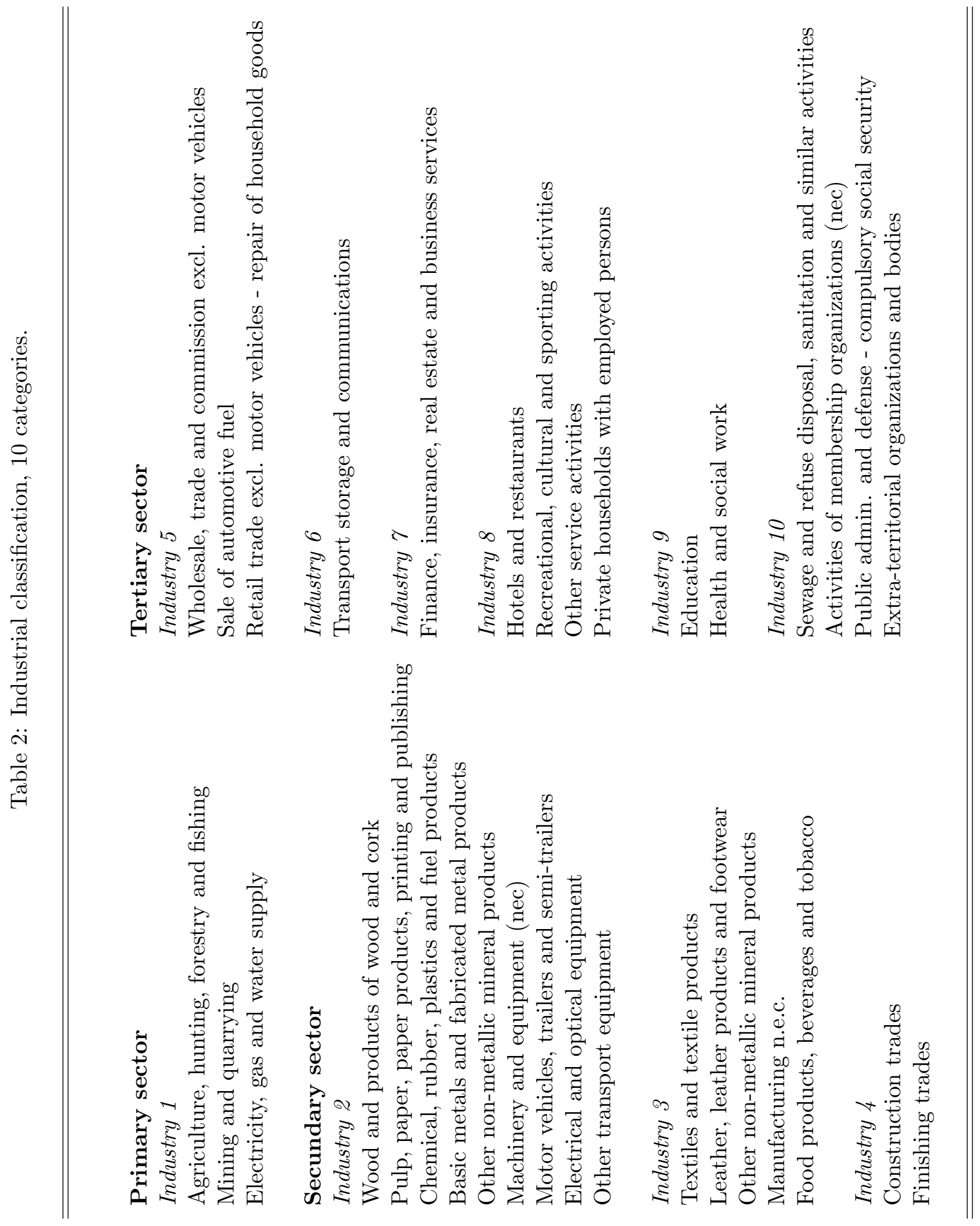


Table 3: Occupational classification, 10 categories.

\begin{tabular}{ll} 
Agricultural & Painters \\
Occupation 1 & Goods sorters, packagers \\
Farming, forestry, gardening, fishing & $\begin{array}{l}\text { Assistants } \\
\text { Machine operators }\end{array}$ \\
Mining and quarrywork & Technicians \\
Occupation 2 & Occupation 6 \\
Mining and quarrywork & Technicians - engineers and related \\
& Technicians - manufacturing and science \\
Manufacturing & Services and professionals \\
Occupation 3 & Occupation 7 \\
Stone, jewelery, brickwork & Buying and selling \\
Glass and ceramics & Banking, insurance, agents \\
Chemicals, plastics and rubber & Arts, creative and recreational \\
Paper and printing & Other services, personal and leisure services \\
Woodwork & \\
Metalworkers, primary product & Occupation 8 \\
Skilled metal work and related & Travel and transport \\
Electrical & Administration and bureaucracy \\
Metal and assembly / installation & Public order, safety and security \\
Occupation 4 & \\
Textiles & Occupation 9 \\
Leather goods & Health services \\
Food, drink and tobacco & Teaching and social employment \\
Occupation 5 & Other \\
Construction & Occupation 10 \\
Building & Other occupations \\
Carpenters & \\
\hline \hline
\end{tabular}


Table 4: Occupational classification, 16 categories.

\begin{tabular}{ll} 
Agricultural & Building \\
Occupation 1 & Carpenters \\
Farming, forestry, gardening, fishing & $\begin{array}{l}\text { Painters } \\
\text { Goods sorters, packagers }\end{array}$ \\
Mining and quarrywork & Assistants \\
Occupation 2 & Machine operators \\
Mining and quarrywork & Technicians \\
Manufacturing & Occupation 10 \\
Occupation 3 & Technicians - engineers and related \\
Stone, jewelery, brickwork & Technicians - manufacturing and science \\
Glass and ceramics & Services and professionals \\
Chemicals, plastics and rubber & Occupation 11 \\
& Buying and selling \\
Occupation 4 & Banking, insurance, agents \\
Paper and printing & Other services, personal and leisure service \\
Woodwork & \\
Occupation 5 & Occupation 12 \\
Metal workers, primary product & Travel and transport \\
Skilled metal work and related & Occupation 13 \\
Occupation 6 & Administration and bureaucracy \\
Electrical & Public order, safety and security \\
Metal and assembly / installation & Occupation 14 \\
Occupation 7 & Arts, creative and recreational \\
Textiles & Occupation 15 \\
Leather goods & Occupation 16 \\
Occupation 8 & \\
Food, drink and tobacco & \\
Occupation 9 & \\
\hline \hline
\end{tabular}




\section{H Robustness analysis}

This Section performs a range of additional regressions to test the robustness of the baseline results.

Industrial and occupational aggregation The model assumes that the mobility parameters $\varphi^{I N D}$ and $\varphi^{O C C}$ are independent of the classification of occupations and industries. However, since the cost of moving across industries and occupations is increasing in industrial and occupational distance, the coefficients of interest may be a decreasing function of the aggregation degree of industries and occupations. If the aggregation level is too high, $\varphi^{I N D} \rightarrow 1$ and $\varphi^{O C C} \rightarrow 1$ and the spillover effect may disappear.

Table 5 investigates how results behave under various levels of industrial and occupational aggregation. Column (1) reproduces the baseline specification with 16 industries and 33 occupations. Columns (2), (3), (4), and (5) present results based on $16 * 16,10 * 10,6 * 16$ and $6 * 6$ classifications, respectively. ${ }^{2}$

Results for the $16 * 16$ classification are close to the $33 * 16$ baseline classification, with a slight decrease in the coefficients of industrial and occupational composition indices. This suggests that the average distance across occupations in a $33 * 16$ and $16 * 16$ classification is similar. As expected, when switching to higher degrees of aggregation, as shown in columns (3)-(5), the effect of a shift in industrial and occupational composition, as respectively captured by the coefficients on $R_{q c \tau}^{I N D}$ and $R_{i c \tau}^{O C C}$, disappear. The coefficient on the city composition index remains statistically insignificant over the specifications but becomes very noisy with aggregation degrees beyond the $10 * 10$ classification. For this reason, the implied mobility parameters are imprecisely measured in columns (3)-(5).

For the $16 * 33$ classification, estimated mobility parameters suggest that mobility is higher across occupations - a result which is likely to be induced by the aggregation level of industries being twice that of occupations. In the case of the $16 * 16$ classification - where mobility parameters are more comparable - estimates (which do statistically significantly differ from each other, with a p-value on $H 0: \varphi^{I N D}=\varphi^{O C C}$ of 0.046$)$ still indicate that mobility across occupations exceeds

\footnotetext{
${ }^{2}$ Except for the classification into 6 industries, no broader official classifications exist. Thus, the other broader reclassifications of industries and occupations are made by the author. The industrial classification into 6 and 10 categories are shown in Section G, Tables 1-2, of the Web Appendix. The occupational classification into 10 and 16 categories are shown in Section G, Tables 3-4, of the Web Appendix.
} 
mobility across industries. This implies that the sectoral wage spillover effect from shifts in the composition of within-industry employment is at least as important as the one resulting from a shift in industrial composition, and should therefore not be omitted.

Table 5: Industrial and occupational aggregation.

\begin{tabular}{|c|c|c|c|c|c|}
\hline \multirow{2}{*}{$\begin{array}{l}\text { Dependent variable } \\
\text { Regressors }\end{array}$} & \multicolumn{5}{|c|}{$\Delta \log w_{q i c \tau}$} \\
\hline & $\begin{array}{c}(\mathbf{1}) \\
16 X 33\end{array}$ & $\begin{array}{c}(2) \\
16 X 16\end{array}$ & $\begin{array}{c}(\mathbf{3}) \\
10 \mathrm{X} 10\end{array}$ & $\begin{array}{c}(4) \\
6 \mathrm{X} 16\end{array}$ & $\begin{array}{l}(5) \\
6 \mathrm{X} 6\end{array}$ \\
\hline$\Delta R_{q c \tau}^{I N D}$ & $\begin{array}{c}1.072^{* *} \\
(0.271)\end{array}$ & $\begin{array}{c}* 0.820^{* *} \\
(0.388)\end{array}$ & $\begin{array}{r}-0.070 \\
(0.748)\end{array}$ & $\begin{array}{r}-0.039 \\
(0.654)\end{array}$ & $\begin{array}{r}-0.403 \\
(0.993)\end{array}$ \\
\hline$\Delta R_{i c \tau}^{O C C}$ & $\begin{array}{c}2.750^{* *} \\
(0.533)\end{array}$ & $\begin{array}{c}* 2.618^{* *} \\
(0.909)\end{array}$ & $\begin{array}{c}2.690 \\
(1.653)\end{array}$ & $\begin{array}{c}1.614 \\
(1.627)\end{array}$ & $\begin{array}{c}0.880 \\
(1.878)\end{array}$ \\
\hline$\Delta R_{c \tau}^{C I T Y}$ & $\begin{array}{c}0.647 \\
(1.140)\end{array}$ & $\begin{array}{c}1.198 \\
(1.104)\end{array}$ & $\begin{array}{c}-2.984 \\
(2.897)\end{array}$ & $\begin{array}{c}1.895 \\
(2.243)\end{array}$ & $\begin{array}{r}-0.035 \\
(6.161)\end{array}$ \\
\hline$\Delta E R_{c \tau}$ & $\begin{array}{c}0.281 \\
(0.410)\end{array}$ & $\begin{array}{c}0.509 \\
(0.433)\end{array}$ & $\begin{array}{c}0.441 \\
(0.283)\end{array}$ & $\begin{array}{c}0.395 \\
(0.265)\end{array}$ & $\begin{array}{c}0.385 \\
(0.398)\end{array}$ \\
\hline $\begin{array}{l}\text { Implied } \varphi^{I N D} \\
\text { Implied } \varphi^{O C C} \\
\text { H0: } \beta_{1}=\beta_{2}\end{array}$ & $\begin{array}{c}0.810 \\
0.624 \\
{[0.005]}\end{array}$ & $\begin{array}{c}0.686 \\
0.406 \\
{[0.062]}\end{array}$ & $\begin{array}{r}-9.150 \\
0.023 \\
{[0.155]}\end{array}$ & $\begin{array}{r}0.460 \\
-0.021 \\
{[0.375]}\end{array}$ & $\begin{array}{c}1.041 \\
0.920 \\
{[0.548]}\end{array}$ \\
\hline $\begin{array}{l}\text { F-first stage: } \Delta R_{q c \tau}^{I N D} \\
\text { F-first stage: } \Delta R_{i c \tau}^{O C C} \\
\text { F-first stage: } \Delta R_{c \tau}^{C I T Y} \\
\text { F-first stage: } \Delta E R_{c \tau} \\
\text { Hansen } \\
\text { Observations }\end{array}$ & $\begin{array}{l}620 \\
201 \\
262 \\
22 \\
0.220 \\
9376\end{array}$ & $\begin{array}{l}408 \\
242 \\
441 \\
21 \\
0.193 \\
7439\end{array}$ & $\begin{array}{l}433 \\
232 \\
121 \\
18 \\
0.231 \\
4172\end{array}$ & $\begin{array}{l}244 \\
129 \\
165 \\
18 \\
0.432 \\
2767\end{array}$ & $\begin{array}{l}152 \\
95 \\
165 \\
10 \\
0.349 \\
1408\end{array}$ \\
\hline
\end{tabular}

Notes: All estimations contain $d_{q i \tau}$. Standard errors are clustered at the city level. Standard errors in parentheses. ${ }^{* * *} \mathrm{p}<0.01,{ }^{* *} \mathrm{p}<0.05,{ }^{*} \mathrm{p}<0.1$.

Selection into cities and occupations The baseline estimates rely on the assumption that the sample is a random draw of the population. In practice however, workers tend to self-select into cities according to unobserved earnings-related reasons. If worker selection is correlated with unobserved determinants of wages (e.g. individual abilities), the conditional mean error term will not be zero. The estimates of the coefficients on the composition indices will be inconsistent if the 
structure of employment within cities is correlated with worker selection decisions into cities. Like Beaudry et al. (2012), the paper uses Dahl (2002)'s non-parametric approach to correct for sample selection bias.

Let $d_{k c t}$ be a dummy taking the value of one if individual $k$ works in city $c$ at time $t$ and let $E\left[\xi_{k q i c t} \mid d_{k c t}=1\right]$ be the conditional mean error term. $d_{k b c t}$ is a dummy variable taking the value of one if individual $k$ born in city $b$ is working in city $c$ at time $t$. Let $P r_{k b c t}$ and $P r_{k b b t}$ be the probabilities that individual $k$ born in city $b$ is observed in city $c$ and remains in city $b$ at time $t$, respectively. Following Dahl (2002), the conditional mean error term can be identified as a function of worker migration probabilities $P r_{k b c t}$ and $P r_{k b b t}$. For movers it is

$$
E\left[\xi_{k q i c t} \mid d_{k c t}=1\right]=\sum_{b} d_{k b c t}\left(P r_{k b c t}^{2}+P r_{k b b t}^{2}\right)+\iota_{k q i c t},
$$

while for stayers it is

$$
E\left[\xi_{k q i c t} \mid d_{k c t}=1\right]=\sum_{b} d_{k b c t} \operatorname{Pr}_{k b b t}^{2}+\iota_{k q i c t}
$$

where $\iota$ is a zero-mean residual term. The sample selection bias is corrected by introducing $\sum_{b} d_{k b c t}\left(P r_{k b c t}^{2}+P r_{k b b t}^{2}\right)$ and $\sum_{b} d_{k b c t} P r_{k b b t}^{2}$ in the wage premium estimations.

Let individuals be divided into cells according to their observed characteristics (i.e. age, gender, nationality, education). Within the cell which is relevant for individual $k$, the migration probabilities are computed as follows

$$
\operatorname{Pr}_{k b c t}=\frac{N_{b c t}}{N_{b t}} \quad \text { and } \quad P r_{k b b t}=\frac{N_{b b t}}{N_{b t}}
$$

where $N_{b t}$ is the number of individuals born in city $b$ observed in the sample at time $t, N_{b b t}$ is the number of individuals born in city $b$ and still observed in city $b$ and $N_{b c t}$ is the number of individuals born in city $b$ but observed in city $c$, at time $t$. Within each cell, differences in $P_{k b c t}$ across movers being observed in city $c$ are due to variations in the city of birth across workers. If the city of birth is not directly correlated to individual wages, differences in probabilities across movers of the same cell reflect differences in their unobserved abilities. Taking BGS case in point,

[...] a person born in Pennsylvania has a lower probability of being observed in Seattle than a person born in Oregon. If both are observed living in Seattle, then we are assuming that 
the person from Pennsylvania must have a larger Seattle specific "ability" (a stronger earnings reason for being there) and this is what is being captured by the sample correction. ${ }^{3}$

The IAB anonymized sample does not provide data on workers city of birth. Instead, workers city of residence at $(t-1)$ is used as a source of variation across workers within cells, i.e. the paper assumes that where movers where living at $(t-1)$ does not affect their wage determination at time $t{ }^{4}$ The paper addresses the issue of self-selection into occupations in a similar way.

Results are shown in Table 6. Column (1) shows the baseline estimates. Columns (2) and (3) present results for specifications that control for selection into cities and occupations, respectively. The point estimates on the industrial and occupational composition indices remain stable and statistically significant at the $1 \%$ level. Even though they remain statistically insignificant and positive, the estimates on the city composition index are reduced considerably, suggesting that they were capturing part of the self-selection effect across cities. Regarding the estimated mobility parameters, they remain similar to the baseline specification. Overall, correcting for sample selection bias does not substantially affect the results.

\footnotetext{
${ }^{3}$ Beaudry et al. (2012)

${ }^{4}$ The choice of one lag for workers city of residence is arbitrary. Estimates remain similar if five lags are used.
} 
Table 6: Selection.

\begin{tabular}{|c|c|c|c|}
\hline Dependent variable & & $\log w_{q i c \tau}$ & \\
\hline Regressors & $\begin{array}{c}(1) \\
\text { Baseline }\end{array}$ & $\begin{array}{c}(\mathbf{2}) \\
\text { City } \\
\text { Selection }\end{array}$ & $\begin{array}{c}\mathbf{( 3 )} \\
\text { Occupation } \\
\text { Selection }\end{array}$ \\
\hline$\Delta R_{c \tau}^{C I T Y}$ & $\begin{array}{c}0.647 \\
(1.140)\end{array}$ & $\begin{array}{c}0.232 \\
(1.543)\end{array}$ & $\begin{array}{c}0.307 \\
(1.194)\end{array}$ \\
\hline$\Delta R_{q c \tau}^{I N D}$ & $\begin{array}{l}1.072^{\text {*** }} \\
(0.271)\end{array}$ & $\begin{array}{l}1.106^{* * *} \\
(0.211)\end{array}$ & $\begin{array}{l}1.303^{* * *} \\
(0.247)\end{array}$ \\
\hline$\Delta R_{i c \tau}^{O C C}$ & $\begin{array}{l}2.750^{* * *} \\
(0.533)\end{array}$ & $\begin{array}{c}3.172^{* * *} \\
(0.775)\end{array}$ & $\begin{array}{l}2.334^{* * *} \\
(0.418)\end{array}$ \\
\hline$\Delta E R_{c \tau}$ & $\begin{array}{c}0.281 \\
(0.410)\end{array}$ & $\begin{array}{c}0.032 \\
(0.377)\end{array}$ & $\begin{array}{c}0.198 \\
(0.419)\end{array}$ \\
\hline $\begin{array}{l}\text { Implied } \varphi^{I N D} \\
\text { Implied } \varphi \text { OCC } \\
\text { H0: } \beta_{1}=\beta_{2}\end{array}$ & $\begin{array}{c}0.810 \\
0.624 \\
{[0.005]} \\
\end{array}$ & $\begin{array}{c}0.932 \\
0.826 \\
{[0.007]} \\
\end{array}$ & $\begin{array}{c}0.884 \\
0.809 \\
{[0.024]} \\
\end{array}$ \\
\hline $\begin{array}{l}\text { F-first stage: } \Delta R_{c \tau}^{C I T Y} \\
\text { F-first stage: } \Delta R_{q c \tau}^{I N D} \\
\text { F-first stage: } \Delta R_{i c \tau}^{O C C} \\
\text { F-first stage: } \Delta E R_{c \tau} \\
\text { Hansen } \\
\text { Observations }\end{array}$ & $\begin{array}{l}262 \\
620 \\
201 \\
22 \\
0.220 \\
9376\end{array}$ & $\begin{array}{c}221 \\
1976 \\
271 \\
22 \\
0.564 \\
9376\end{array}$ & $\begin{array}{l}305 \\
1861 \\
241 \\
22 \\
0.224 \\
9376\end{array}$ \\
\hline
\end{tabular}


Identification issue The identification strategy hinges on the assumption that national employment and changes in national employment, in a particular occupation-industry cell, are uncorrelated to present and future city-specific idiosyncratic shocks on wages. To test for the validity of this assumption, the paper predicts city-level employment in a particular occupation and industry using French employment growth. If the identification strategy is valid, then using French employment growth to construct instruments should not alter the estimates. ${ }^{5}$

Results are presented in Table 7. Columns (1) shows the baseline results. Column (2) shows IV results for the specification that uses French occupation-industry employment growth to create instruments. Results lend support to the identification strategy. The point estimates are very close to the baseline specification. The coefficients on composition indices increase slightly. The coefficients on the industrial and occupational composition indices remain significant with p-values smaller than 0.01. Even though they decrease somewhat, the estimated parameters $\varphi^{I N D}$ and $\varphi^{O C C}$ remain high, suggesting significant mobility costs.

\footnotetext{
${ }^{5}$ Data source: INSEE French employment survey, 1975-2002 period.
} 
Table 7: Instrumenting with French data.

\begin{tabular}{|c|c|c|}
\hline Dependent variable & & $g w_{q i c \tau}$ \\
\hline Regressors & $\begin{array}{c}(1) \\
\text { Baseline }\end{array}$ & $\begin{array}{c}\text { (2) } \\
\text { French data }\end{array}$ \\
\hline$\Delta R_{q c \tau}^{I N D}$ & $\begin{array}{l}1.072^{* * *} \\
(0.271)\end{array}$ & $\begin{array}{l}1.123^{* * *} \\
(0.326)\end{array}$ \\
\hline$\Delta R_{i c \tau}^{O C C}$ & $\begin{array}{l}2.750^{* * *} \\
(0.533)\end{array}$ & $\begin{array}{l}3.141^{* * *} \\
(0.710)\end{array}$ \\
\hline$\Delta R_{c \tau}^{C I T Y}$ & $\begin{array}{c}0.647 \\
(1.140)\end{array}$ & $\begin{array}{c}1.007 \\
(1.334)\end{array}$ \\
\hline$\Delta E R_{c \tau}$ & $\begin{array}{c}0.281 \\
(0.410)\end{array}$ & $\begin{array}{c}0.247 \\
(0.438)\end{array}$ \\
\hline $\begin{array}{l}\text { Implied } \varphi^{I N D} \\
\text { Implied } \varphi^{O C C} \\
\text { H0: } \beta_{1}=\beta_{2}\end{array}$ & $\begin{array}{c}0.810 \\
0.624 \\
{[0.005]} \\
\end{array}$ & $\begin{array}{c}0.757 \\
0.527 \\
{[0.008]} \\
\end{array}$ \\
\hline $\begin{array}{l}\text { F-first stage: } \Delta R_{q c \tau}^{I N D} \\
\text { F-first stage: } \Delta R_{i c \tau}^{O C C} \\
\text { F-first stage: } \Delta R_{c \tau}^{C I T Y} \\
\text { F-first stage: } \Delta E R_{c \tau} \\
\text { Hansen } \\
\text { Observations }\end{array}$ & $\begin{array}{l}620 \\
201 \\
262 \\
22 \\
0.220 \\
9376\end{array}$ & $\begin{array}{c}161 \\
56 \\
108 \\
11 \\
0.142 \\
8907\end{array}$ \\
\hline
\end{tabular}




\section{References}

P. Beaudry, D. Green, and B. Sand. Does Industrial Composition Matter for Wages: An Empirical Evaluation Based on Search and Bargaining Theory. Econometrica, 80(3):1063-1104, 2012.

S. Bender, A. Haas, and C. Klose. IAB Employment Subsample 1975-1995: Opportunities for Analysis Provided by the Anonymised Subsample. IZA Discussion Paper Series, 2000.

G. B. Dahl. Mobility and the Return to Education: Testing a Roy Model with Multiple Markets. Econometrica, 70(6):2367-2420, 2002. 